\title{
SEISMIC FRAGILITY OF PLASTERBOARD PARTITIONS VIA IN-PLANE QUASI-STATIC TESTS
}

\author{
Petrone C. ${ }^{1}$, Magliulo G. ${ }^{1, *}$, Lopez P. ${ }^{2}$, Manfredi G. ${ }^{1}$ \\ ${ }^{1}$ Department of Structures for Engineering and Architecture, University of Naples Federico II, \\ Naples, Italy \\ ${ }^{2}$ Product Development Department, Etex Dry Co, 500 Rue Marcel Demonque, 84915 Avignon, \\ France
}

\begin{abstract}
The seismic damage of internal partitions may cause significant earthquake loss; this phenomenon is caused by (a) their tendency to exhibit damage for low demand levels and (b) the consequent loss of inventory and breakdown that their collapse can cause.

Quasi-static tests are performed on six $5 \mathrm{~m}$ high plasterboard internal partitions, which represent the typical partitions in industrial and commercial buildings in the European area. A steel test setup is designed to transfer the load, which is provided by the actuator, to the partition. The testing protocol provided by FEMA 461 is adopted for the quasi-static tests.

The typical failure mode of the specimens is the buckling of a steel stud, which involves the boards that are attached to the buckled stud. The buckling failure usually concentrates across the plasterboard horizontal joints. A frictional behavior is exhibited for low demand levels, whereas a pinched behavior is shown for moderate to high demand levels.

The interstory drift ratios (IDRs) required to reach a given damage limit state are evaluated using a predefined damage scheme. Based on the experimental data, the fragility curves for three different damage states (DS1, DS2 and DS3) are estimated. The fragility curve yields the median IDR values of $0.28 \%, 0.81 \%$ and $2.05 \%$ and logarithmic standard deviations of $0.39,0.42$ and 0.46 for DS1, DS2 and DS3, respectively.
\end{abstract}

\section{KEYWORDS}

Nonstructural components, internal partitions, quasi-static test, testing protocol, seismic performance, fragility curves.

\footnotetext{
* Correspondence to: Gennaro Magliulo, Department of Structures for Engineering and Architecture, via Claudio 21, 80125 Naples, Italy. E-mail gmagliul@unina.it. tel +390817683656. fax +390817685921
} 


\section{INTRODUCTION}

Nonstructural components are currently recognized as a crucial issue in the framework of performance-based earthquake engineering [1]. Most of the construction cost of a building is related to nonstructural components [2]. These components usually exhibit damage at low seismic intensity levels and cause the loss of functionality of structures with undamaged structural components. The loss related to the failure of nonstructural components may easily exceed the total cost of the building, particularly if breakdown and loss of inventory are considered [3]. In some cases, the collapse of nonstructural components may cause injuries or fatalities: in the 2012 Emilia (Italy) earthquake, the failure of nonstructural components, i.e., cladding panels in precast structures, was the main cause of fatalities and damage [4]. Internal partitions can be classified as architectural nonstructural components according to Villaverde [5]; plasterboard internal partitions are notably widespread worldwide. The study described herein focuses on "tall” plasterboard internal partitions in industrial and commercial buildings.

Many past studies focused on assessing the seismic performance of nonstructural components [6-9]. The seismic performance of plasterboard internal partitions, which are characterized with coldformed steel studs, has been investigated in different studies. Lee et al. [10] tested different $2.8 \mathrm{~m}$ high drywall plasterboard partitions using quasi-static and dynamic tests; three different configurations were considered: i.e., plain partition, partition with a door and partition with an intersecting wall. The damage-related loss was also discussed, and the repair cost almost reached the initial cost at 2\% interstory drift ratio. Restrepo and Lang [11] investigated the influence of two different loading protocols on the response of the full-scale gypsum light gage metal-stud partition walls. The specimens show a small sensitivity to the two proposed quasi-static loading protocols. Restrepo and Bersofsky [12] performed quasi-static tests on eight pairs of light gage steel stud partition walls, representative of typical partitions installed in United States. Three different damage limit states were identified and correlated to the interstory drift ratio. Tasligedik et al. [13] performed experimental tests on two typical drywall partitions, whose internal structures were either steel- or timber-framed. It was confirmed that the drywall systems in current practice exhibited damage that would require repairing interventions for low drift levels. The differences between the two partition typologies were highlighted, and some comments on the serviceability limit state criterion provided by New Zealand Code were provided. Magliulo et al. [14, 15] performed bidirectional shake table tests on innovative drywall internal partitions, to evaluate their seismic performance considering the in-plane and out-of-plane interaction. For this purpose, a steel test frame was designed to simulate the seismic effects at a generic building story. The innovative partition systems exhibited a minor damage state for $0.58 \%$ interstory drift ratio and a moderate damage state for $0.98 \%$ interstory drift ratio. Retamales et al. [16] performed an extensive campaign, i.e., 28 quasi-static tests, on common interior partitions in residential, commercial, office and institutional buildings. The failure mechanisms were reported and correlated to three damage states. Then, fragility curves were provided for different partition groups.

In this study, quasi-static tests were performed on $5 \mathrm{~m}$ tall plasterboard internal partitions. This partition typology represents the typical partitions in industrial and commercial buildings in European countries. A proper steel test frame was defined to perform quasi-static tests on these components. Six different specimens, which represented the typical partition typologies, were subjected to the quasi-static testing protocol of FEMA 461 [17]. The observed damage was briefly described and correlated to predefined damage states. Finally, the fragility curves for three different damage states are evaluated.

\section{EXPERIMENTAL FACILITY, TEST SETUP, SPECIMENS AND TESTING PROTOCOL}

The quasi-static test campaign was conducted in the Laboratory of the Department of Structures for Engineering and Architecture at the University of Naples Federico II. The tests aimed at assessing the seismic behavior of the internal plasterboard partitions in industrial buildings. Figure 1 shows 
the test setup, which had a steel frame (see §2.1), the specimen, i.e., a plasterboard partition, a hydraulic actuator and a reaction wall. The tested plasterboard partitions were $5.0 \mathrm{~m}$ high and $5.1 \mathrm{~m}$ wide. They were composed of perimeter steel tracks, vertical steel studs, and plasterboards, which were screwed to the studs and the tracks.

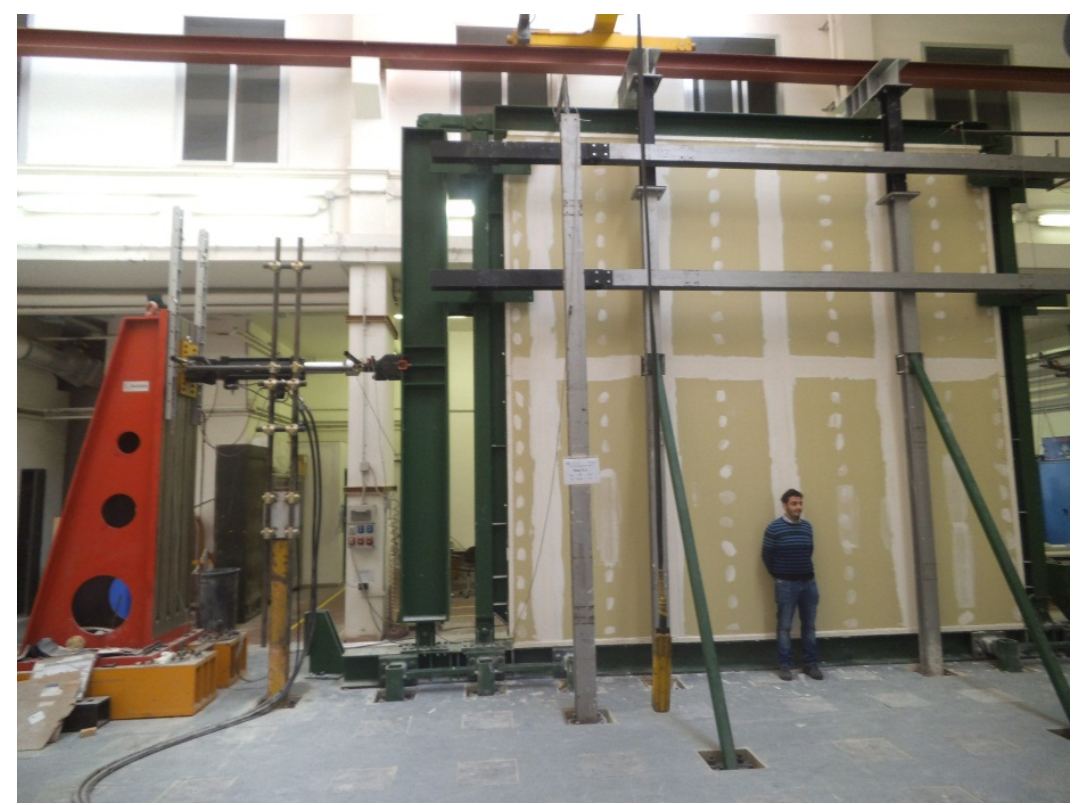

Figure 1. Test setup global view

\subsection{Test setup: concept, design and test on bare setup}

The steel test frame was conceived to transfer the load from the hydraulic jack to the partition without absorbing lateral forces; hence, a statically indeterminate scheme was developed (Figure 2a). Moreover, because the reaction wall cannot reach the height of the system, the actuator was placed at the middle height of the test setup. Hence, a given displacement produced by the actuator was doubled at the top of the setup, and a rigid loading column was assumed.

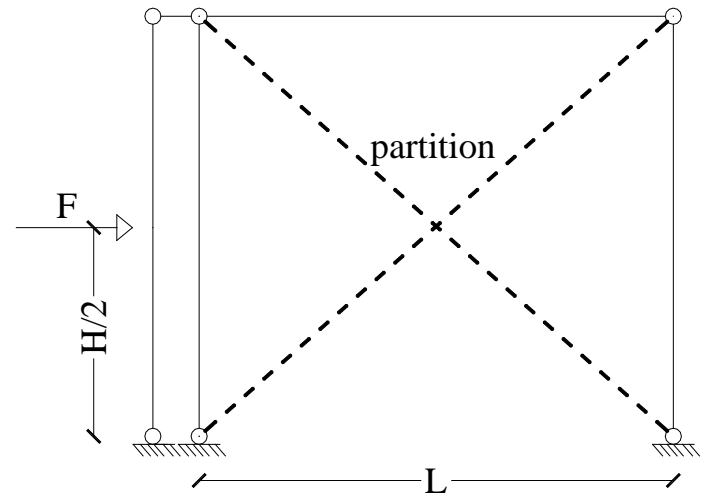

(a)

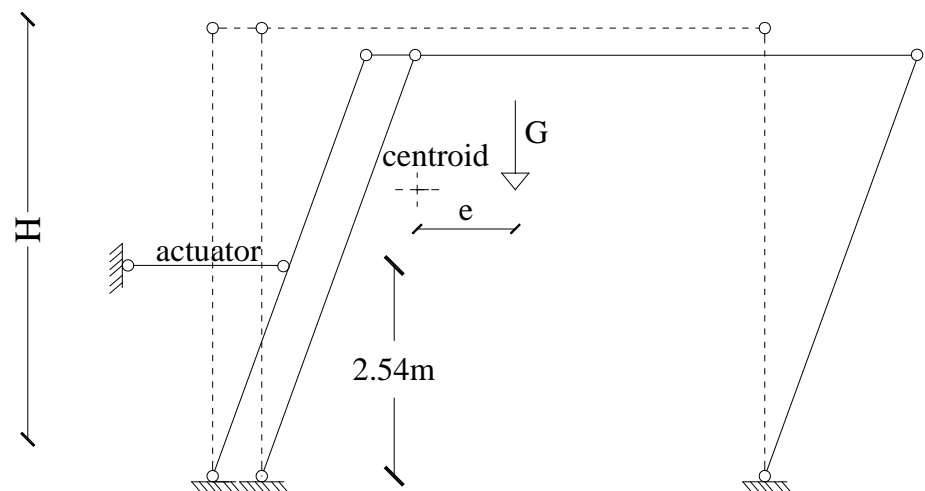

(b)

Figure 2. (a) Conception scheme of the test setup; (b) kinematic mechanism of the test frame without the partition.

The actuator is connected to a loading column at its mid span, and the loading column is connected to the frame surrounding the partition through a horizontal pendulum. Consequently, the loading column acts as a simply supported beam, which is loaded by a force in the centerline. The presence of the partitions introduce a lateral restraint in the unstable setup. Both translational and rotational equilibrium should be satisfied in the static scheme in Figure 2a. In particular, the equilibrium of the loading column ensures that a half of the actuator force is transmitted at the top of the setup, and the other half is transmitted at the base restraint. 
The setup design is defined according to Eurocode $3[18,19]$. As shown in Figure 3, it is composed of:

- an I-shaped "HE 450B" vertical loading steel column, which is $4.785 \mathrm{~m}$ long;

- two tubular 180x180x10 mm lateral steel columns, which are $4.785 \mathrm{~m}$ long;

- an I-shaped "HE 280B" top horizontal steel beam, which is $5.370 \mathrm{~m}$ long;

- a horizontal steel tubular profile $150 \times 150 \times 12.5 \mathrm{~mm}$ S355, which is placed between the loading column and the nearby lateral column;

- an I-shaped "HE 280B" base horizontal steel beam, which is $7.800 \mathrm{~m}$ long.

Different steel elements are connected to one another using pin connections; the base restraint is provided with bolted connections between the columns and the base steel beam.

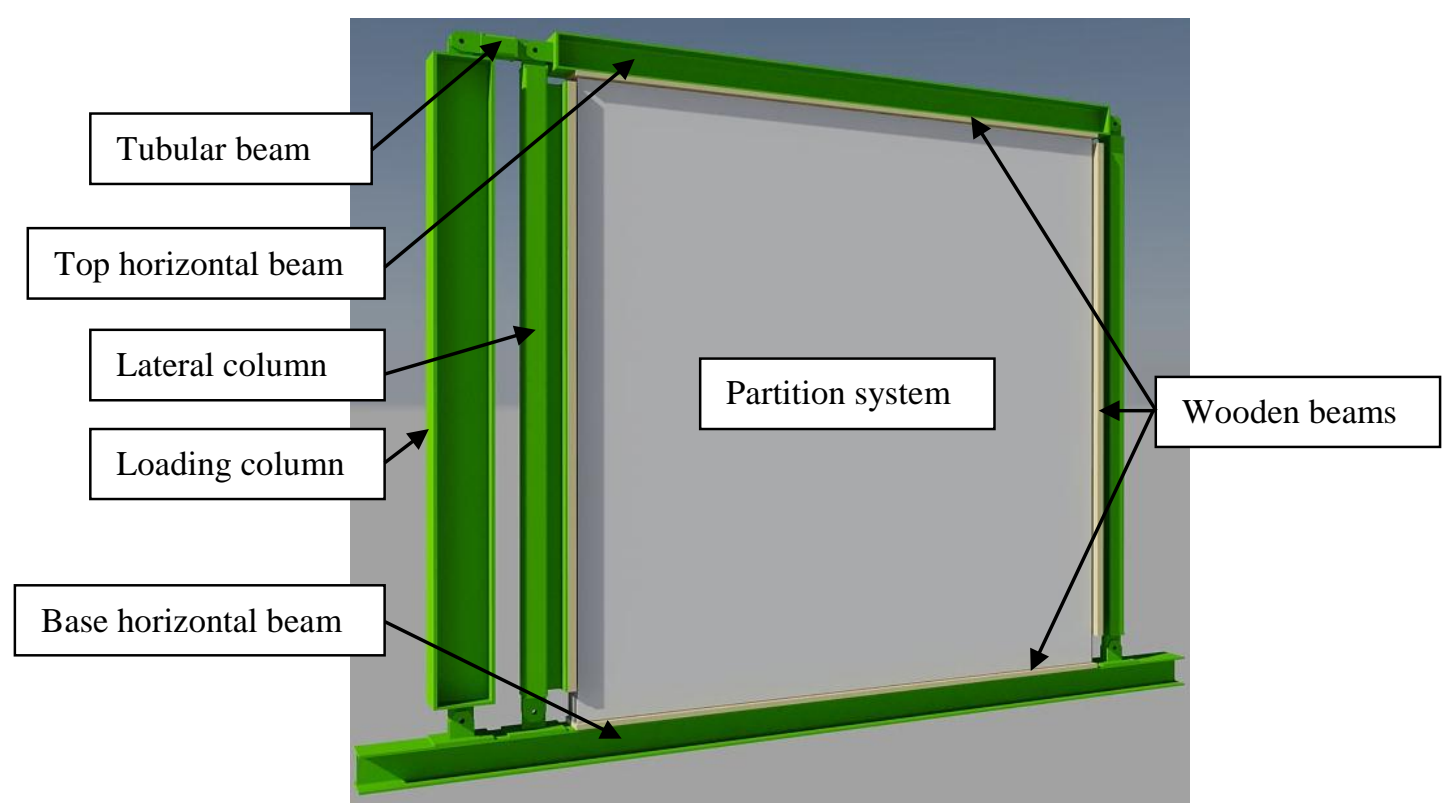

Figure 3. Test frame 3D view.

Wooden beams are fixed to both vertical tubular columns and horizontal beams to tighten the partition steel tracks. Finally, the base beam is connected to the floor through bolted anchoring systems.

An out-of-plane reaction system is defined (Figure 1) to avoid undesired out-of-plane displacements. It consists of two I-shaped "HE 140A" columns and two I-shaped "HE 160A" horizontal beams for each side of the test setup. Four steel rollers (Figure 4) allow the specimen to slide and avoid undesired out-of-plane displacements. In addition, two diagonal stiffening inclined steel beams are provided in the out-of-plane direction (Figure 1). The weight of the entire steel test frame is approximately $80 \mathrm{kN}$. 


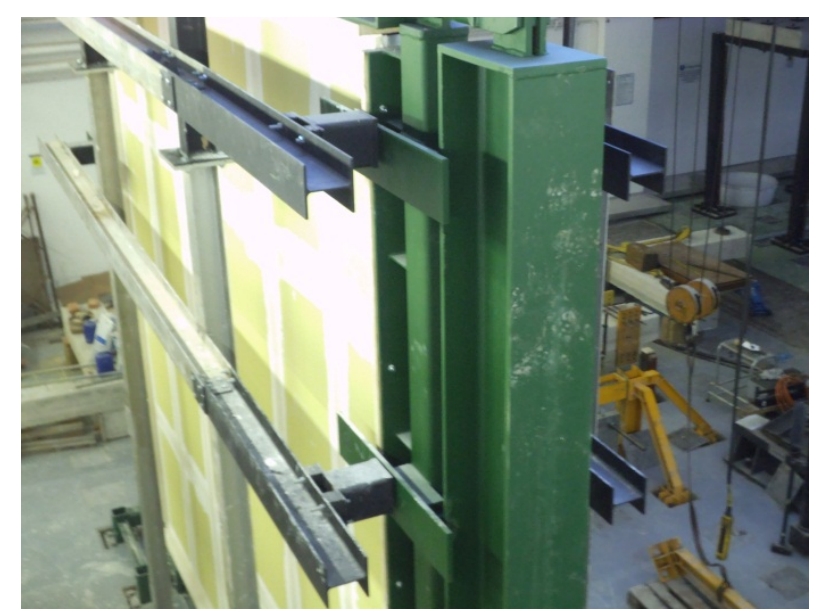

Figure 4. Lateral view on the rollers of the out-of-plane reaction system.

A preliminary test on the test frame without plasterboard partition was performed to verify the kinematic mechanism of the test frame and the absence of friction mechanisms in the test setup. The test consisted of pushing and pulling the test frame up to $10 \mathrm{~cm}$ at the actuator height. In addition, the inclination of the vertical elements was recorded using an inclinometer to verify that all vertical elements exhibited the identical rotation throughout the test. The recorded force-displacement relationship is plotted in Figure 5.

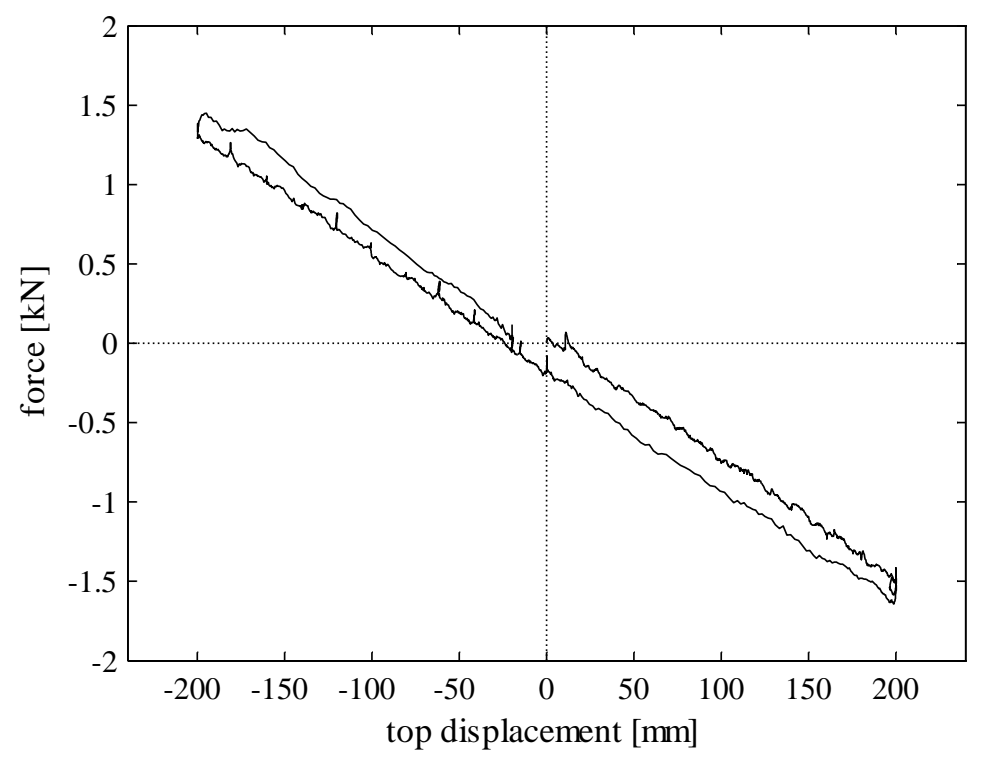

Figure 5. Test on the bare test setup: force-displacement relationship.

The negative stiffness in the force-displacement relationship can be justified using the static scheme in Figure 2b. Indeed, when the test frame was loaded, the actuator exhibited a lateral restraint for the column to which it was connected; in particular, it acted as a horizontal pendulum. The imposed displacement produced an eccentricity, i.e., $e$ in Figure 2b. The moment of gravitational loads is balanced by the moment of the actuator horizontal reaction because the actuator represents a restraint for the test frame. Hence, the steel frame makes the actuator in tension during the pushing phase and in compression when the test frame is pulled.

The centroid of the bare test frame is at $3.24 \mathrm{~m}$ from the base hinges, and the weight of the portion of the test setup in the mechanism is $29.72 \mathrm{kN}$. The force in the actuator for a displacement in the actuator of $100 \mathrm{~mm}$, i.e., $200 \mathrm{~mm}$ top displacement, is evaluated as follows:

$$
G \cdot e=R_{\text {actuator }} \cdot H / 2 \Rightarrow R_{\text {actuator }}=G \cdot \frac{e}{H / 2}=\frac{29.72 \mathrm{kN} \cdot\left(0.10 \mathrm{~m} \cdot \frac{3.24 \mathrm{~m}}{2.54 \mathrm{~m}}\right)}{2.54 \mathrm{~m}}=1.48 \mathrm{kN}
$$


This result indicates that the recorded force in the actuator is related to the mechanism of the bare test frame, which can be neglected with respect to the force that the partition usually withstands because this value is notably small for the expected level of displacement during the test campaign. Finally, the force-displacement relationship clearly denotes that friction is negligible.

\subsection{Instrumentation}

Different instruments were used to monitor the behavior of the specimens during the cyclic tests. The monitoring system consists of the following instrumentation typologies (Figure 6):

- two displacement laser sensors, which were placed at half the height of the column and the top of the same column to verify the rigid movement of the vertical column and monitor the top in-plane displacement;

- two wire potentiometers, which were placed in parallel to the laser sensors;

- two displacement transducers (LVDTs) at the two edges of the top horizontal beam, which measure the out-of-plane displacements to verify the planarity of the motion;

- twelve strain gauges (Figure 6), which were equally divided among the steel studs (sg1 sg6) and outer plasterboard layer (sg7 - sg12); in particular, sg7 corresponds to the same position of sg1, sg8 corresponds to sg2, etc.

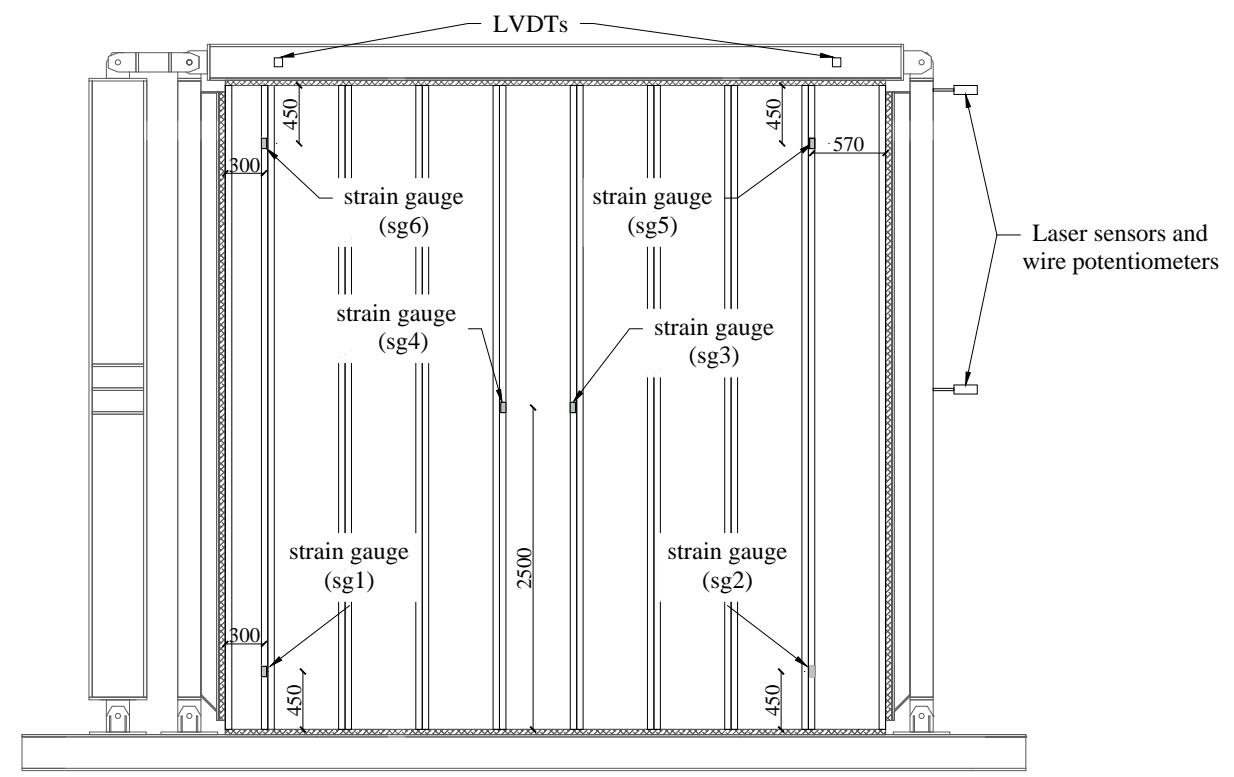

Figure 6. Specimen no. 1: instrumentation position.

\subsection{Testing protocol}

The protocol definition of the quasi-static test is based on the regulations of FEMA 461 "Interim Testing Protocols for Determining the Seismic Performance Characteristics of Structural and Nonstructural Components” [17]. FEMA 461 proposes a loading history with two consecutive steps with amplitude $a_{i}$ and $a_{i+1}$ according to the following relationship:

$$
a_{i+1}=c \cdot a_{i}
$$

Two cycles at the identical amplitude $a_{i}$ are provided for each step. Equation (0) is calibrated to represent the response of the SDOF systems that are subjected to a set of ground motion in ordinary conditions in the US area, i.e., the near-fault ones are not considered [20]. The suggested value of the parameter $c$ is 1.4 .

A set of fourteen European records from [21] was considered to estimate a value of the parameter $c$ according to European conditions. The set of accelerograms (Table 1) is compatible with the Eurocode 8 design spectrum, soil B type and with a design ground acceleration on type A ground of $0.35 \mathrm{~g}$. 


\begin{tabular}{cccccccc}
\hline $\begin{array}{c}\text { Earthquake } \\
\text { code }\end{array}$ & Earthquake name & $\begin{array}{c}\text { Moment } \\
\text { magnitude }\end{array}$ & $\begin{array}{c}\text { Epicentral } \\
\text { distance } \\
(\mathrm{km})\end{array}$ & Date & $\begin{array}{c}\text { Ground } \\
\text { type }\end{array}$ & $\begin{array}{c}\text { PGA_X } \\
{\left[\mathrm{m} / \mathrm{s}^{2}\right]}\end{array}$ & $\begin{array}{c}\text { PGA_Y } \\
{\left[\mathrm{m} / \mathrm{s}^{2}\right]}\end{array}$ \\
\hline 000187 & Tabas & 7.3 & 57 & $16 / 09 / 1978$ & $\mathrm{~B}$ & 9.08 & 10.81 \\
\hline 000196 & Montenegro & 6.9 & 25 & $15 / 04 / 1979$ & $\mathrm{~B}$ & 4.45 & 3.00 \\
\hline 000199 & Montenegro & 6.9 & 16 & $15 / 04 / 1979$ & $\mathrm{~B}$ & 3.68 & 3.56 \\
\hline 000230 & Montenegro (aftershock) & 6.2 & 8 & $24 / 05 / 1979$ & $\mathrm{~B}$ & 1.17 & 2.62 \\
\hline 000291 & Campano Lucano & 6.9 & 16 & $23 / 11 / 1980$ & $\mathrm{~B}$ & 1.53 & 1.72 \\
\hline 006263 & South Iceland & 6.5 & 7 & $17 / 06 / 2000$ & $\mathrm{~B}$ & 6.14 & 5.02 \\
\hline 006334 & South Iceland (aftershock) & 6.4 & 11 & $21 / 06 / 2000$ & $\mathrm{~B}$ & 4.12 & 7.07 \\
\hline
\end{tabular}

Table 1 - Set of European ordinary ground motions in the input definition study.

Linear dynamic analyses were performed on a single-degree-of-freedom (SDOF) system using the set of European records in Table 1. The SDOF system was characterized by a period of 1.0 sec and representative of bare precast RC structures [22], where the tested partitions were ideally installed. For each record, the displacement response was rearranged using the rainflow cycle counting method [23] and normalized with respect to the largest amplitude of the cycle. Only "pre-peak" excursions were considered, as suggested in [17].

The parameter $c$ was calibrated to minimize the scatter between the amplitudes in Equation (0) and the mean normalized pre-peak displacement that resulted from the analyses. In total, 15 steps were considered. The minimum scatter is given by the following relationship:

$$
a_{i+1}=1.39 \cdot a_{i}
$$

In Figure 7, the discrepancy between the analytical results and the protocol provided by equation (0) is shown.

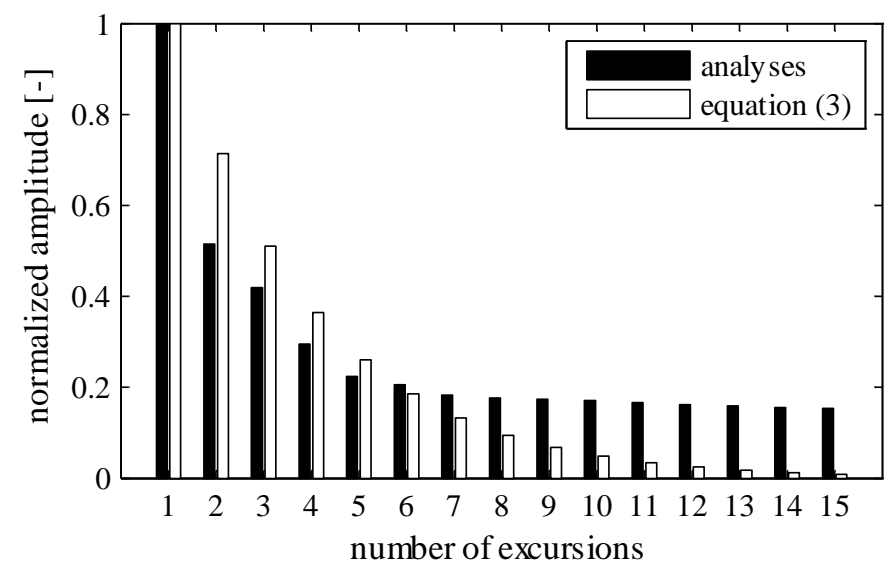

Figure 7. Comparison between the ordered normalized amplitudes that resulted from the analyses and the amplitudes provided by equation (0)

The chosen loading protocol is reported in Table 2 in terms of the interstory drift ratios and normalized amplitudes.

\begin{tabular}{cccccccccccccccc}
\hline step ID & 1 & 2 & 3 & 4 & 5 & 6 & 7 & 8 & 9 & 10 & 11 & 12 & 13 & 14 & 15 \\
\hline drift [\%] & 0.03 & 0.04 & 0.06 & 0.08 & 0.11 & 0.15 & 0.22 & 0.30 & 0.42 & 0.58 & 0.80 & 1.12 & 1.55 & 2.16 & 3.00 \\
\hline $\mathrm{a}_{\mathrm{i}} / \mathrm{a}_{15}$ & 0.01 & 0.01 & 0.02 & 0.03 & 0.04 & 0.05 & 0.07 & 0.10 & 0.14 & 0.19 & 0.27 & 0.37 & 0.52 & 0.72 & 1.00 \\
\hline
\end{tabular}

Table 2. Loading history protocol

\subsection{Specimens}

The specimens represent the plasterboard partitions that are typically commercialized in Europe for industrial buildings. They can be classified into two groups based on the horizontal cross section of the partitions in Figure 8: 
- $\quad$ symmetric partitions, i.e., specimens nos. 1-4 (Figure 8a-d);

- $\quad$ staggered partitions, i.e., specimens nos. 5-6 (Figure 8e-f).

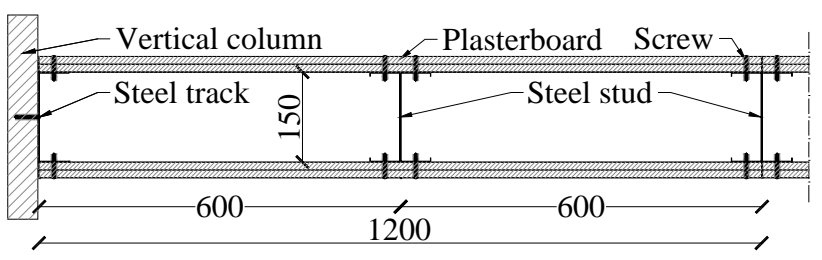

(a)

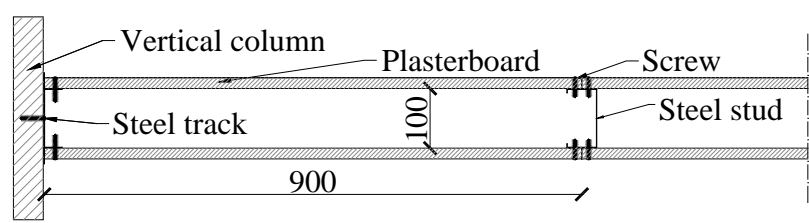

(c)

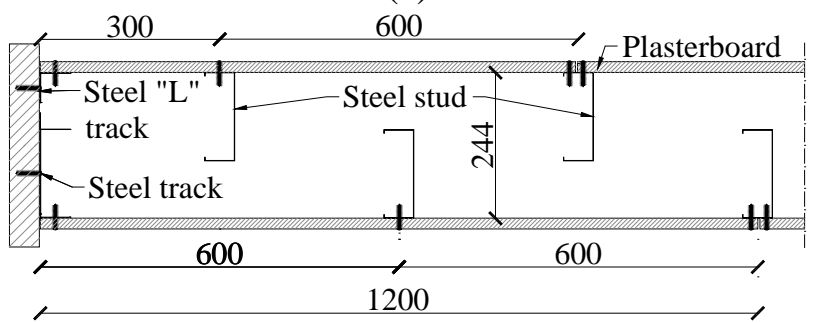

(e)

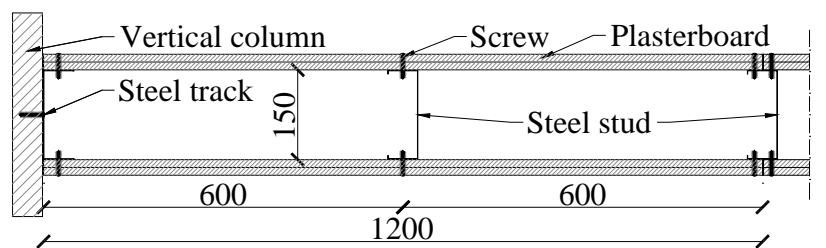

(b)

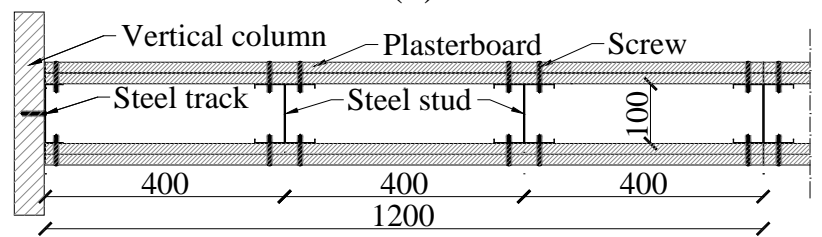

(d)

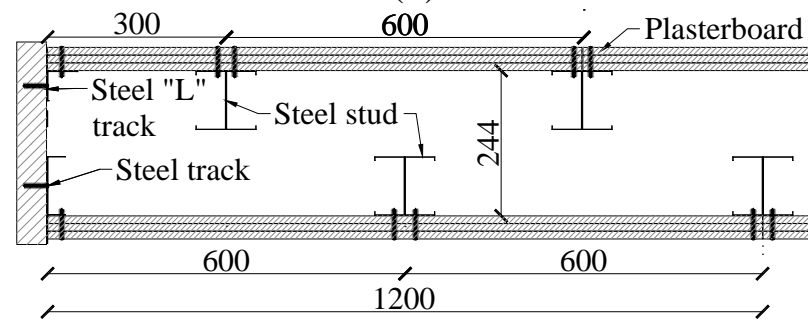

(f)

Figure 8. Horizontal cross-section of different test specimens: (a) specimen no. 1, (b) specimen no. 2, (c) specimen no. 3, (d) specimen no. 4, (e) specimen no. 5 and (f) specimen no. 6 (dimensions are in mm).

The two groups incorporate different types of horizontal and vertical tracks, where single or backto-back studs are placed. Symmetric partitions are characterized by C-shaped tracks, whereas staggered ones have both C-shaped and L-shaped vertical tracks. Both types of partitions provide either single or double layers of boards; three layers of boards are adopted in only one case. Three different board typologies were used for different specimens (Table 3). A standard $12.5 \mathrm{~mm}$ thick plasterboards was used for specimens no. 1, no. 2 and no. 6; specimens no. 4 and no. 5 were characterized by standard $18 \mathrm{~mm}$ thick plasterboards, whereas innovative boards were adopted for specimen no. 3. Innovative boards have a larger hardness and better fire performance than the standard boards. The plasterboards were assembled to define one or two horizontal joints (Figure 9) because of the limited height of the panels. They were screwed to either the studs or the tracks. We avoided connecting the plasterboard with a single screw to both a stud and a horizontal guide. Both the screw and the stud spacings of each partition are listed in Table 3. The studs are $5 \mathrm{~m}$ long; they are only placed in the horizontal tracks without any direct mechanical connection. Both vertical and horizontal tracks are connected to the perimeter wooden beams through $250 \mathrm{~mm}$ spaced screws. Vertical and horizontal plasterboard joints are filled with paper and compound.

Different components satisfy the European standards; in particular, the plasterboards satisfy the EN 520 standards [24], the steel studs/tracks satisfy the EN 14195 standards [25] and the screws satisfy the requirements in EN 14566 [26]. The components of the tested partitions are preliminary tested to evaluate their mechanical properties. Steel studs are characterized with $300 \mathrm{MPa}$ tensile strength and $210 \mathrm{GPa}$ elastic modulus based on tensile tests on the stud specimens. Both compression and tensile tests on the plasterboards were performed for the three different board typologies in the test campaign; in particular, 16 tensile tests and 16 compressive tests were executed. The $13 \mathrm{~mm}$ thick board is characterized by a $3.31 \mathrm{MPa}$ compressive strength and $1.84 \mathrm{MPa}$ tensile strength; the standard $18 \mathrm{~mm}$ thick board exhibits a $5.50 \mathrm{MPa}$ compressive strength and $1.57 \mathrm{MPa}$ tensile strength, whereas the innovative $18 \mathrm{~mm}$ thick board exhibits a 8.16 MPa compressive strength and a 
1.43 MPa tensile strength. The elastic modulus range is 2.41-5.24 GPa. The self-drilling screws are characterized by a $3.5 \mathrm{~mm}$ diameter and a length of $35-45 \mathrm{~mm}$; their hardness is $600-760 \mathrm{HV}$.

In Table 3, the components for each specimen are described. A global view of different specimens in the test setup is shown in Figure 9.

\begin{tabular}{|c|c|c|c|}
\hline Components & Specimen no. 1 & Specimen no. 2 & Specimen no. 3 \\
\hline Plasterboard panels & $\begin{array}{c}2 \text { layers of standard boards } \\
12.5 \mathrm{~mm} \text { thick }\end{array}$ & $\begin{array}{c}2 \text { layers of standard boards } \\
12.5 \mathrm{~mm} \text { thick }\end{array}$ & $\begin{array}{l}1 \text { layer of innovative } \\
\text { boards } 18 \mathrm{~mm} \text { thick }\end{array}$ \\
\hline Steel studs & $\begin{array}{c}50-150-50 \mathrm{~mm} \text { “C” } \\
\text { section, } 0.6 \mathrm{~mm} \text { thick, back } \\
\text { to back, } 600 \mathrm{~mm} \text { spacing }\end{array}$ & $\begin{array}{c}50-150-50 \mathrm{~mm} \text { “C” } \\
\text { section, } 0.6 \mathrm{~mm} \text { thick, } \\
\text { single, } 600 \mathrm{~mm} \text { spacing }\end{array}$ & $\begin{array}{c}50-100-50 \mathrm{~mm} \text { "C" } \\
\text { section, } 0.6 \mathrm{~mm} \text { thick, } \\
\text { single, } 900 \mathrm{~mm} \text { spacing }\end{array}$ \\
\hline Steel tracks & $\begin{array}{l}50-150-50 \mathrm{~mm} \text { "U” cross- } \\
\text { section, } 0.6 \mathrm{~mm} \text { thick }\end{array}$ & $\begin{array}{l}50-150-50 \mathrm{~mm} \text { "U” cross- } \\
\text { section, } 0.6 \mathrm{~mm} \text { thick }\end{array}$ & $\begin{array}{l}30-100-30 \mathrm{~mm} \text { "U” cross- } \\
\text { section, } 0.6 \mathrm{~mm} \text { thick }\end{array}$ \\
\hline Screw spacing & $\begin{array}{c}600 \mathrm{~mm} \text { (inner layer) and } \\
300 \mathrm{~mm} \text { (outer layer) }\end{array}$ & $\begin{array}{c}600 \text { mm (inner layer) and } \\
300 \text { mm (outer layer) }\end{array}$ & $250 \mathrm{~mm}$ \\
\hline Joints & Paper and compound & Paper and compound & Paper and compound \\
\hline Components & Specimen no. 4 & Specimen no. 5 & Specimen no. 6 \\
\hline Plasterboard panels & $\begin{array}{l}2 \text { layers of standard boards } \\
18 \mathrm{~mm} \text { thick }\end{array}$ & $\begin{array}{c}1 \text { layer of standard boards } \\
18 \mathrm{~mm} \text { thick }\end{array}$ & $\begin{array}{c}3 \text { layers of standard boards } \\
12.5 \mathrm{~mm} \text { thick }\end{array}$ \\
\hline Steel studs & $\begin{array}{l}\text { 50-100-50 mm “C”" cross- } \\
\text { section, } 0.6 \mathrm{~mm} \text { thick, } \\
\text { back-to-back, } 400 \mathrm{~mm} \\
\text { spacing }\end{array}$ & $\begin{array}{c}\text { 50-150-50 mm "C" cross- } \\
\text { section, } 0.6 \text { mm thick, } \\
\text { single and staggered, } 600 \\
\text { mm spacing }\end{array}$ & $\begin{array}{l}\text { 50-100-50 mm “C”" cross- } \\
\text { section, } 0.6 \text { mm thick, } \\
\text { back-to-back and } \\
\text { staggered, } 600 \mathrm{~mm} \text { spacing }\end{array}$ \\
\hline Steel tracks & $\begin{array}{l}\text { 30-100-30 mm "U” cross- } \\
\text { section, } 0.6 \mathrm{~mm} \text { thick }\end{array}$ & $\begin{array}{l}50-150-50 \mathrm{~mm} \text { "U” cross- } \\
\text { section, } 0.6 \mathrm{~mm} \text { thick and } \\
50-50 \mathrm{~mm} \text { "L" cross- } \\
\text { section, } 0.6 \mathrm{~mm} \text { thick }\end{array}$ & $\begin{array}{l}50-100-50 \mathrm{~mm} \text { "U” cross- } \\
\text { section, } 0.6 \mathrm{~mm} \text { thick and } \\
50-50 \mathrm{~mm} \text { "L" cross- } \\
\text { section, } 0.6 \mathrm{~mm} \text { thick }\end{array}$ \\
\hline Screw spacing & $\begin{array}{l}600 \mathrm{~mm} \text { (inner layer) and } \\
300 \mathrm{~mm} \text { (outer layer) }\end{array}$ & $300 \mathrm{~mm}$ & $\begin{array}{c}600 \text { mm (inner } 2 \text { layers) } \\
\text { and } 300 \text { mm (outer layer) }\end{array}$ \\
\hline Joints & Paper and compound & Paper and compound & Paper and compound \\
\hline
\end{tabular}

Table 3. Description of different components for each tested specimen.

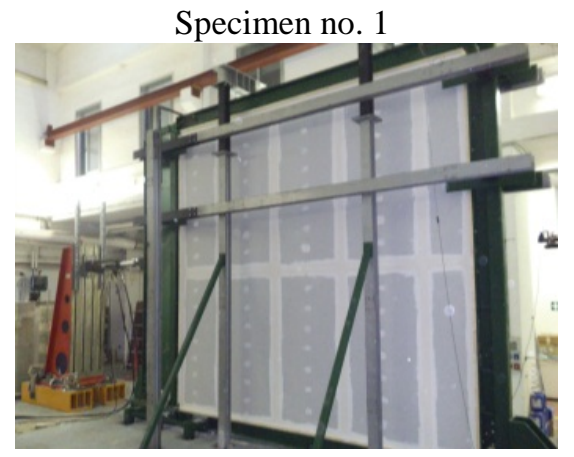

Specimen no. 4

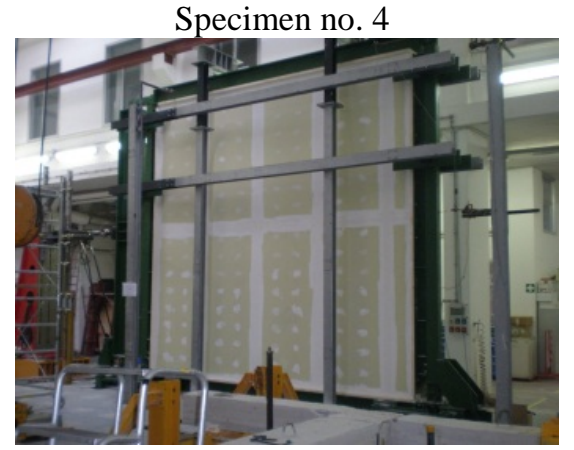

Figure 9. Global view of the specimens nos. 1-6 (from top left to bottom right).

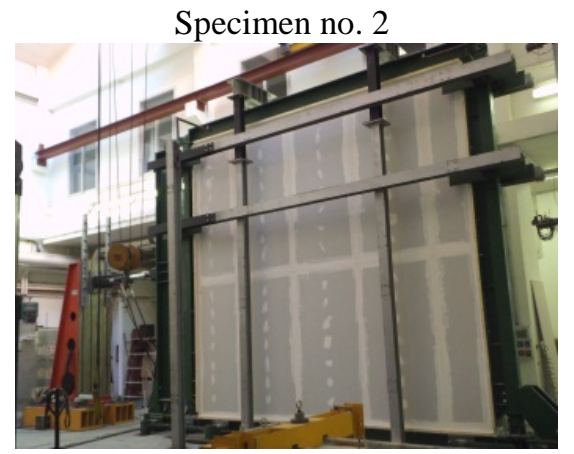

Specimen no. 5

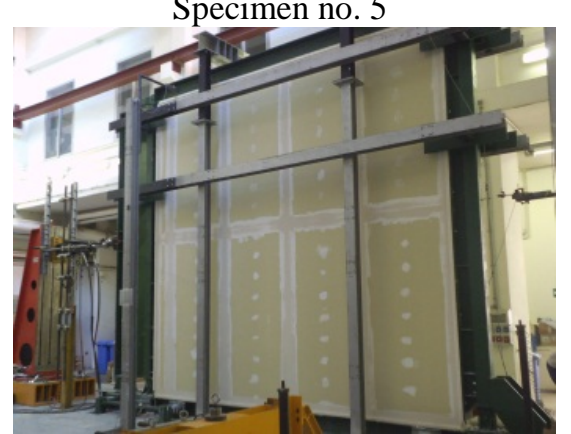

Specimen no. 3

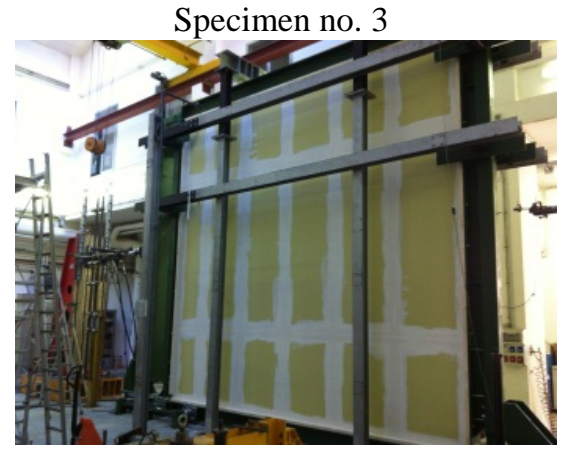

Specimen no. 6

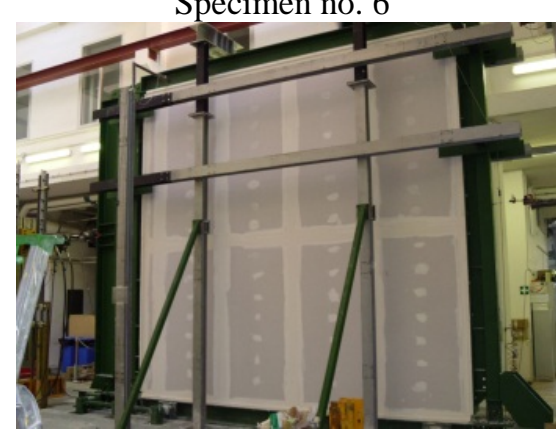




\section{$3 \quad$ RESULTS AND DISCUSSION}

\subsection{Damage description}

Both symmetric (nos. 1-4) and staggered (nos. 5-6) specimens show similar damage trend, which can be summarized in the following phases.

- The first damage occurs along the perimeter: the paper starts cracking (Figure 10a) and detaches the partition along the edges.

- Further cracks occur in the vertical and horizontal joints among the panels, which allows the adjacent panels to exhibit relative displacements for slightly larger drift levels (Figure 10b). The damage is localized at these joints. After corner cracks form, a significant creaking sound is heard: this sound is related to the bearing failure of the board-to-steel screwed connections; this failure mode is clearly shown in the inner layers of the plasterboard during the dismantling phase (Figure 10c).

- The specimens collapse in the out-of-plane direction because of the buckling of one or more steel studs. Indeed, the buckling failure mechanism typically involves a single stud of the partition (Figure 10d). A global buckling of the partition is only observed in test no. 3 (Figure 10e), where all steel studs show a buckling failure in the out-of-plane direction.

During the dismantling phase, the local buckling in the studs is clearly observed. The stud buckling failure mainly concentrates across the plasterboard horizontal joints (Figure 10f).

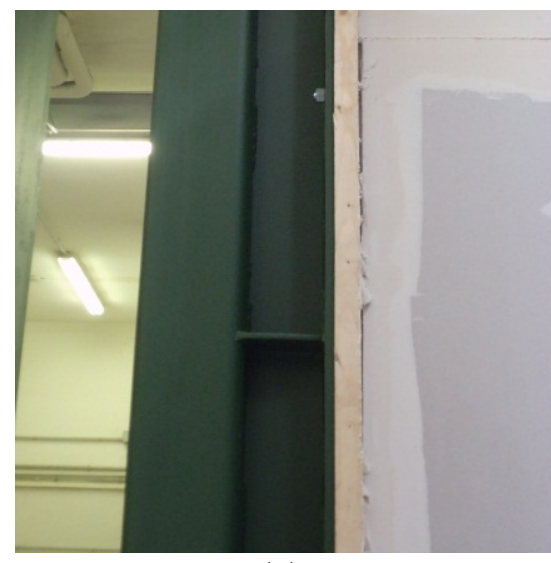

(a)

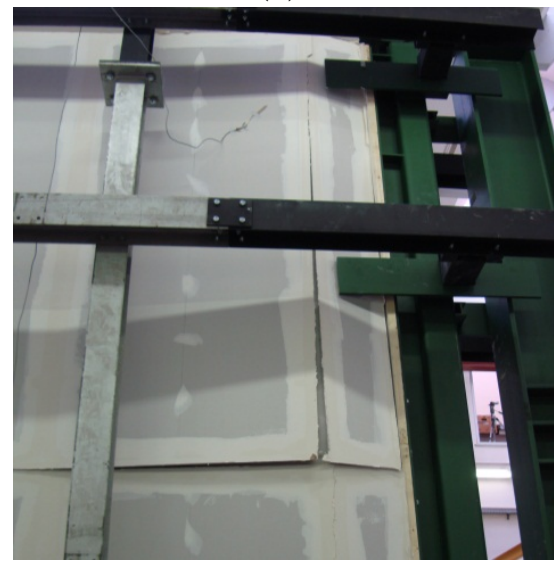

(d)

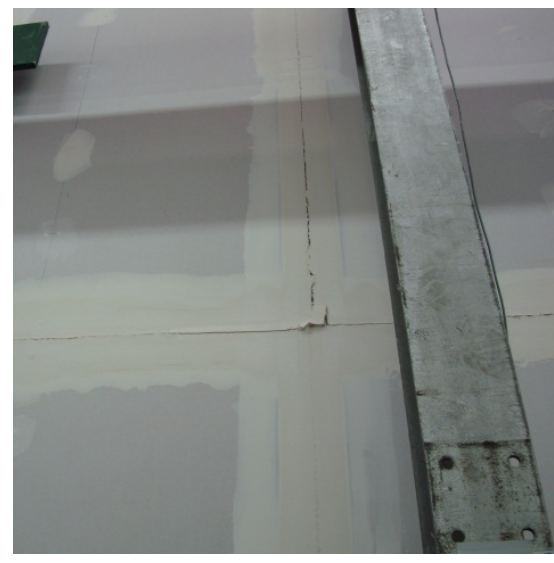

(b)

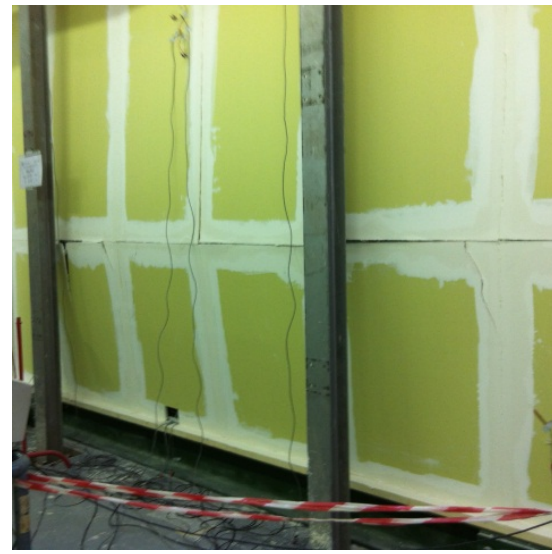

(e)

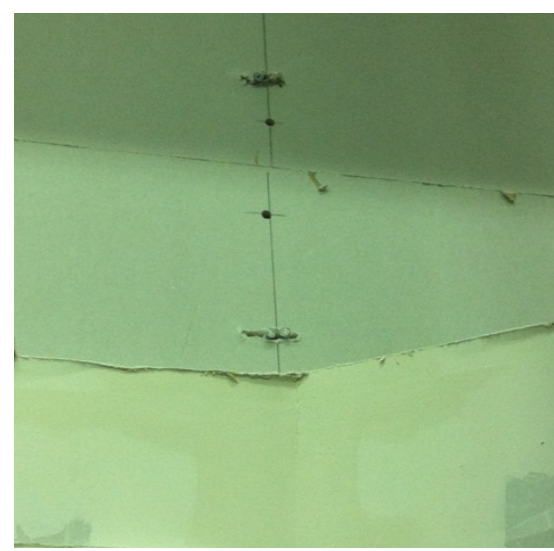

(c)

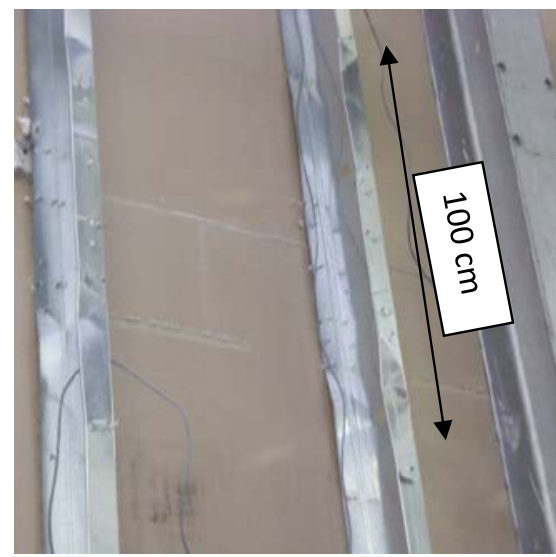

(f)

Figure 10. Damage progression in the specimen: (a) paper cracking along the perimeter (test no. 1); (b) paper cracking in the vertical and horizontal joints (test no. 6); (c) bearing failure of the boards-to-steel screwed connections (test no. 2); (d) local buckling of the partition (test no. 2); (e) global bucking of the partition (test no. 3); (f) buckling of the stud across a plasterboard horizontal joint (test no. 2). 


\subsection{Results summary}

Quasi-static tests were performed on the six specimens using the defined testing protocol. Hysteretic curves are obtained by plotting half of the force provided by the actuator (\$2.1) versus the top displacement (Figure 11).

The following features can be noted from the trend of the hysteretic curves:

- the high initial secant stiffness of different specimens decreases when the relative displacement increases;

- the degrading behavior, which is exhibited after the maximum force is reached, i.e., the post-capping negative stiffness;

- a significant degrading behavior between two cycles at identical displacements;

- the buckling-dominated failure modes of different specimens are clearly visible when the recorded force suddenly decreases after the specimen buckles; it should be noted that the buckling of the partition is also visually detected;

- the frictional behavior in the first cycles (e.g., Figure 12a) and significantly pinched behavior (e.g., Figure 12b), which are exhibited when the screwed connections begin damaging. 
Test no. 1

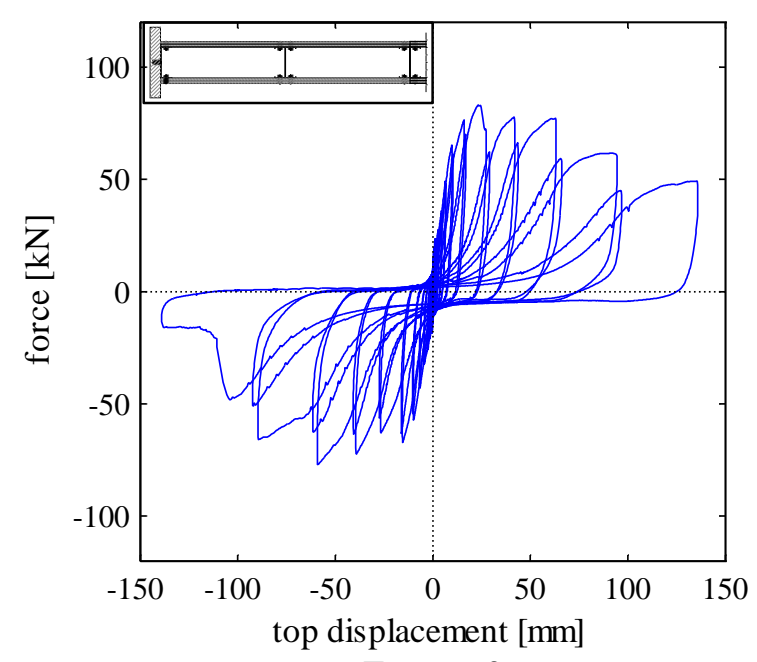

Test no. 3

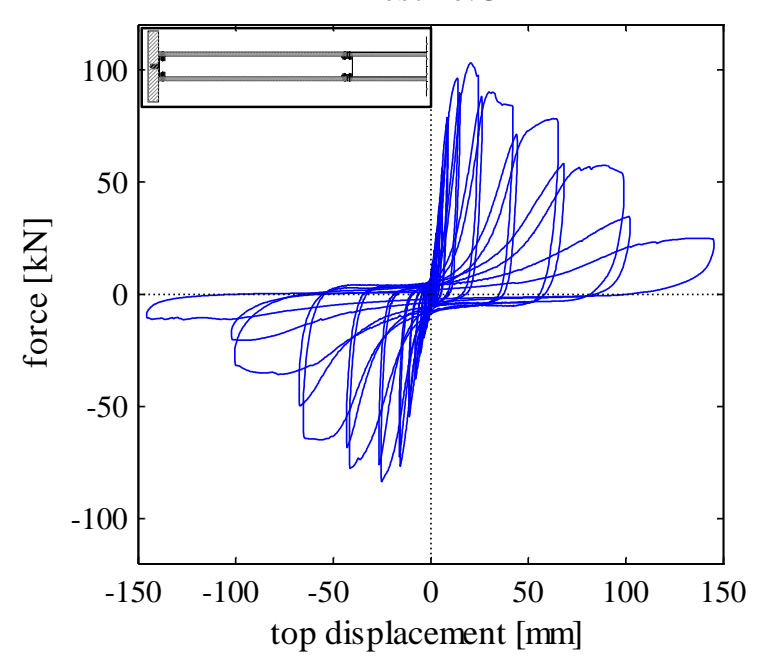

Test no. 5

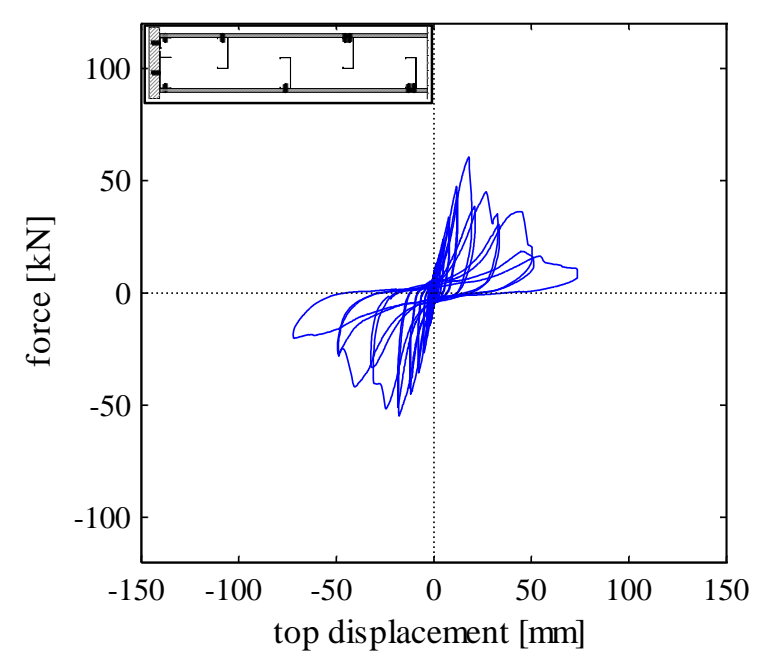

Test no. 2
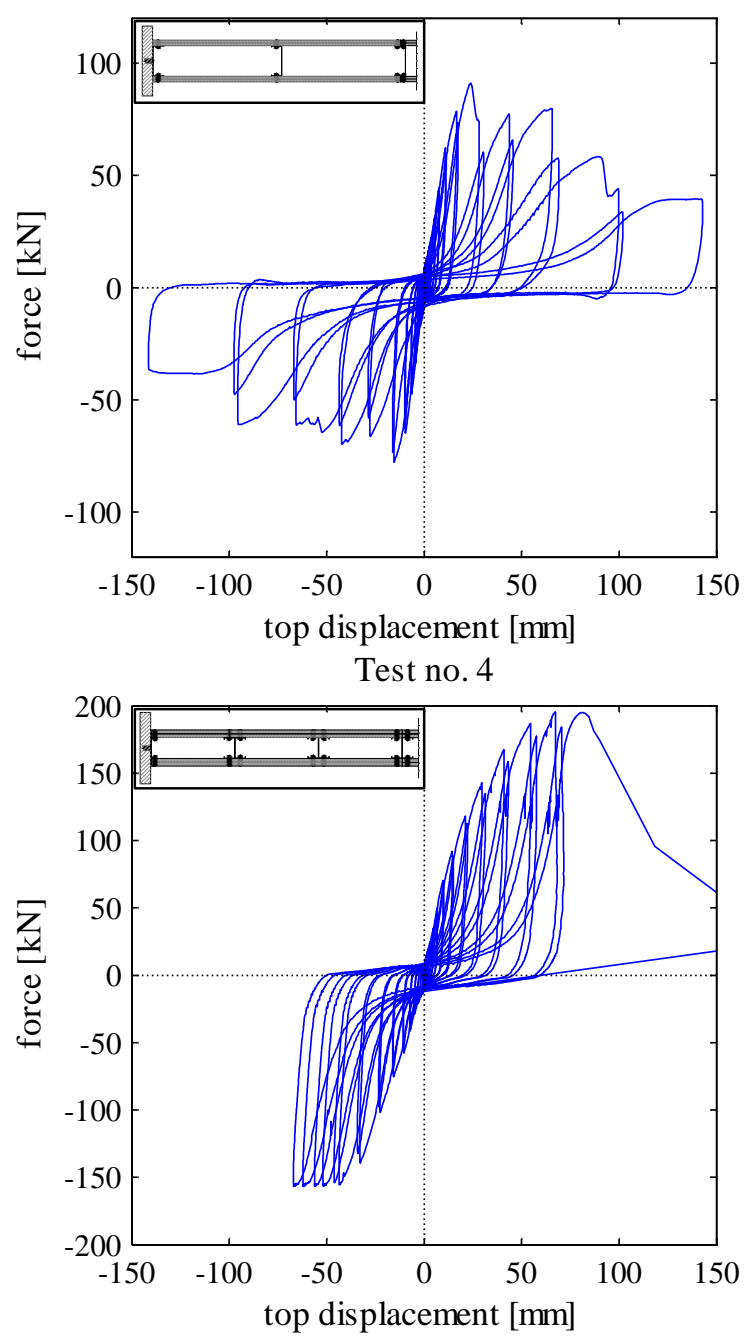

Test no. 6

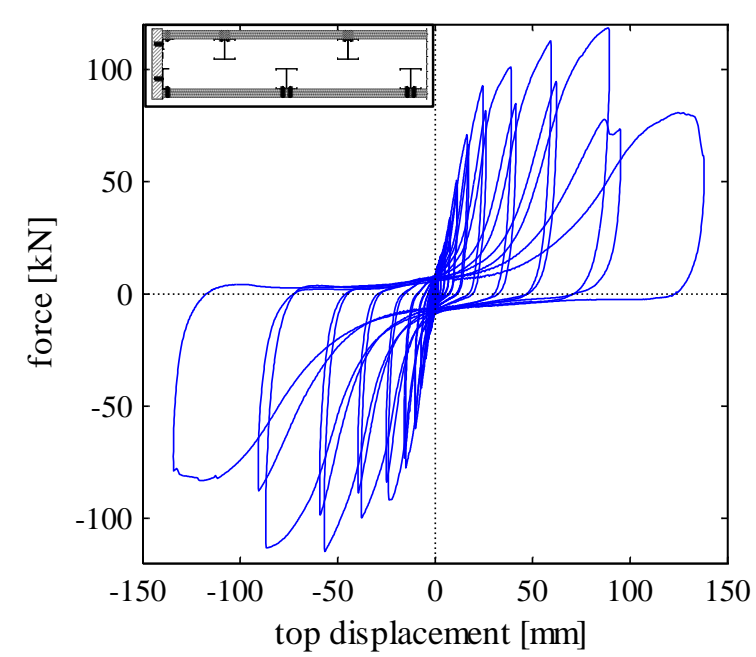

Figure 11. Hysteretic loops from test no. 1 to test no. 6. 


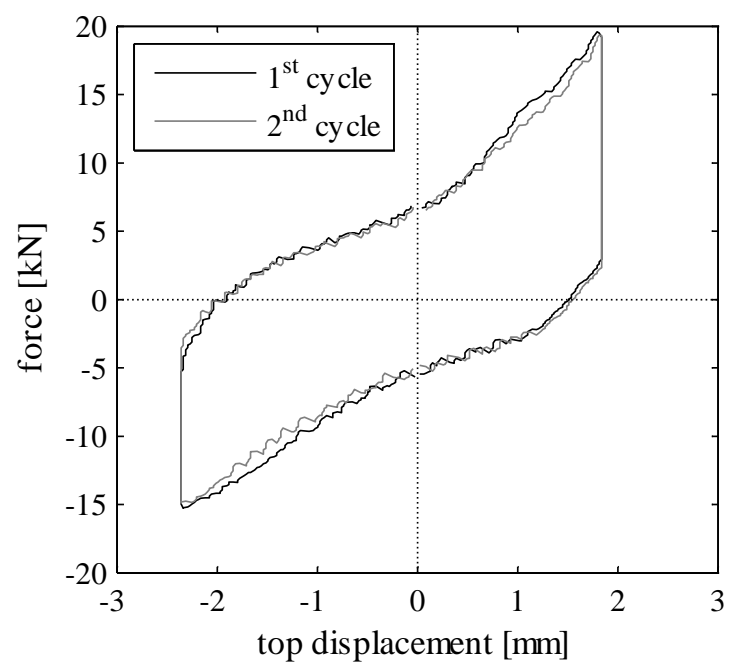

(a)

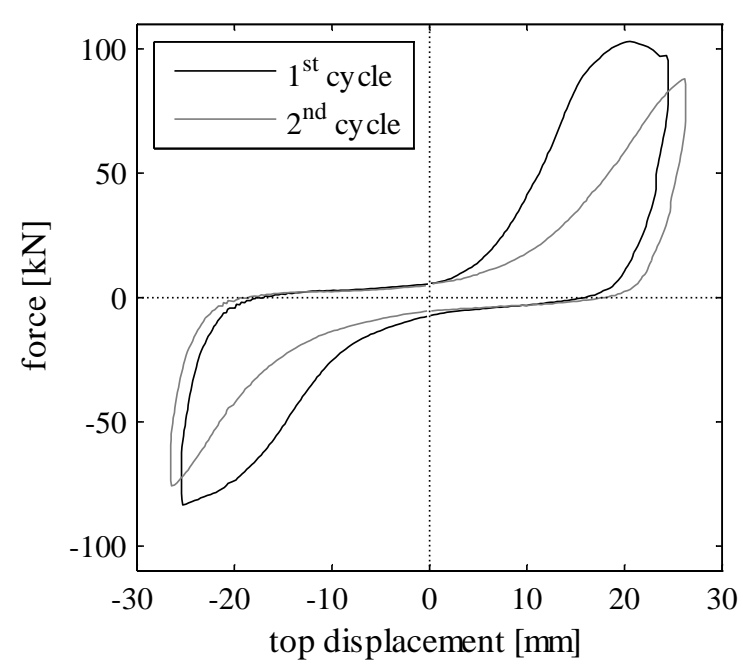

(b)

Figure 12. Hysteretic loops recorded during (a) step no. 5 and (b) step no. 11 in specimen no. 3.

The backbone curves are plotted up to the partition failure in Figure 13a. Both symmetric (nos. 1-4) and staggered (nos. 5-6) partitions show similar backbone curves. In particular, the symmetric partitions have similar initial stiffness. The secant stiffness of the specimen for each step of the protocol was also evaluated (Figure 13b). The secant stiffness was evaluated for both positive and negative top displacements.

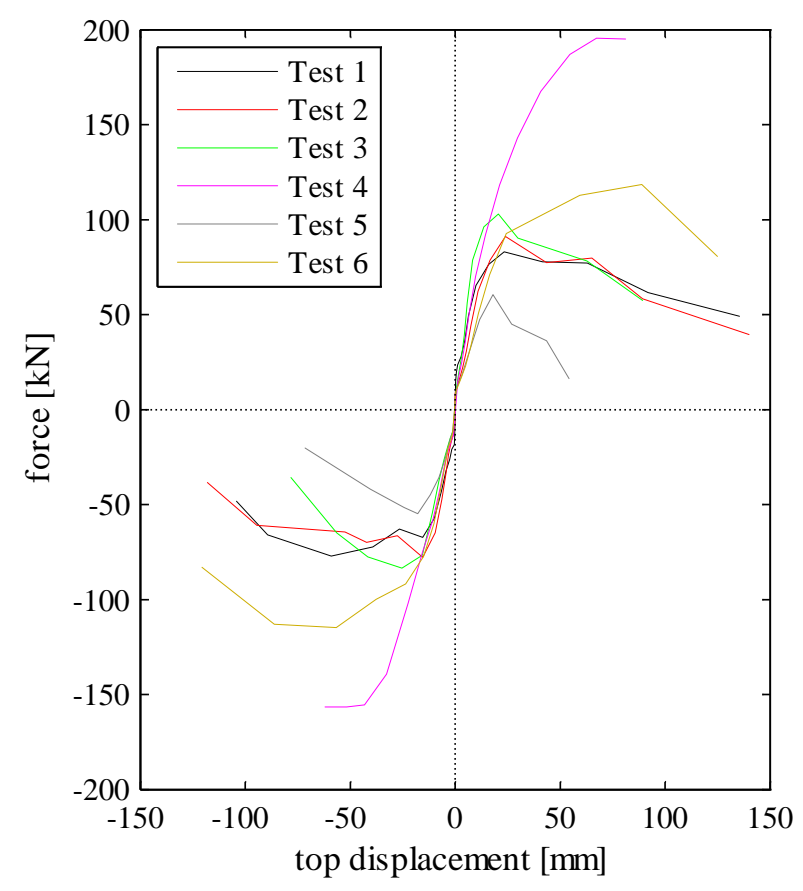

(a)

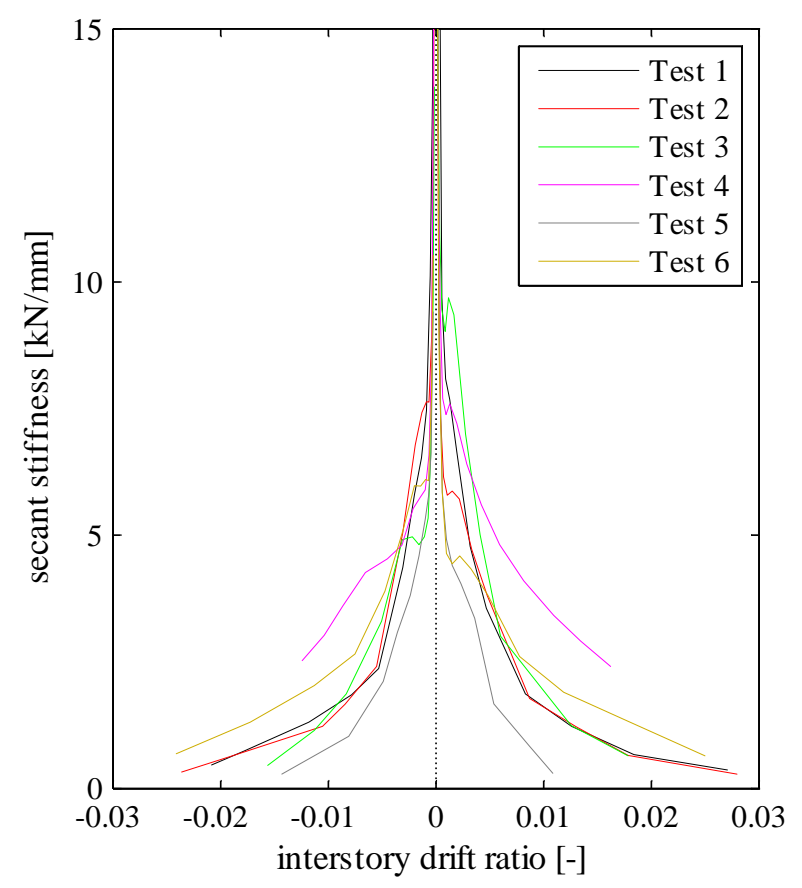

(b)

Figure 13. Comparison among (a) the backbones and (b) secant stiffness recorded during different tests.

- The staggered and symmetric partitions exhibit similar secant stiffness trends (Figure 13b); however, the trends of the staggered ones have a slightly lower collapse displacement than the symmetric partitions.

- The back-to-back steel studs do not provide significant variations in the in-plane behavior, as shown in the comparison between test no. 1 and test no. 2 backbones. 
- The use of a large amount of boards and studs significantly increases the strength and decreases the collapse displacement, as shown in the comparison between test no. 3 and test no. 4 backbones.

- The staggered specimens no. 5 and no. 6 have significantly different strength and collapse displacement.

Both groups of specimens show the identical trend of secant stiffness (Figure 13b). Three phases can be identified:

- an initial friction-dominated phase, where high secant stiffness values are recorded until the paper in the plasterboard joints begins cracking;

- a phase where the secant stiffness exhibits a horizontal branch at interstory drift ratios of $0.10-0.25 \%$; in this phase, the paper in the joints is cracked, and the adjacent panels come into contact with one another;

- a final pinching-dominated phase, when the damage is concentrated in the panel-to-stud screwed connections; the secant stiffness decreases until the specimen failure.

Figure 14 shows the dissipated energy in test no. 1 for each cycle of the protocol and each negative and positive semi-cycle. The strongly degrading behavior of the specimen is clearly shown:

- the testing protocol provides two consecutive cycles at the identical displacement (see Section 2.3); the energy dissipated in the second cycle of the step is significantly smaller than the energy dissipated in the first cycle of the same step;

- the energy dissipated in the negative semi-cycle is smaller than the energy dissipated in the preceding positive semi-cycle.

The same conclusions can be drawn from the dissipated energy trends of the other five tests, which are not reported for the sake of brevity.

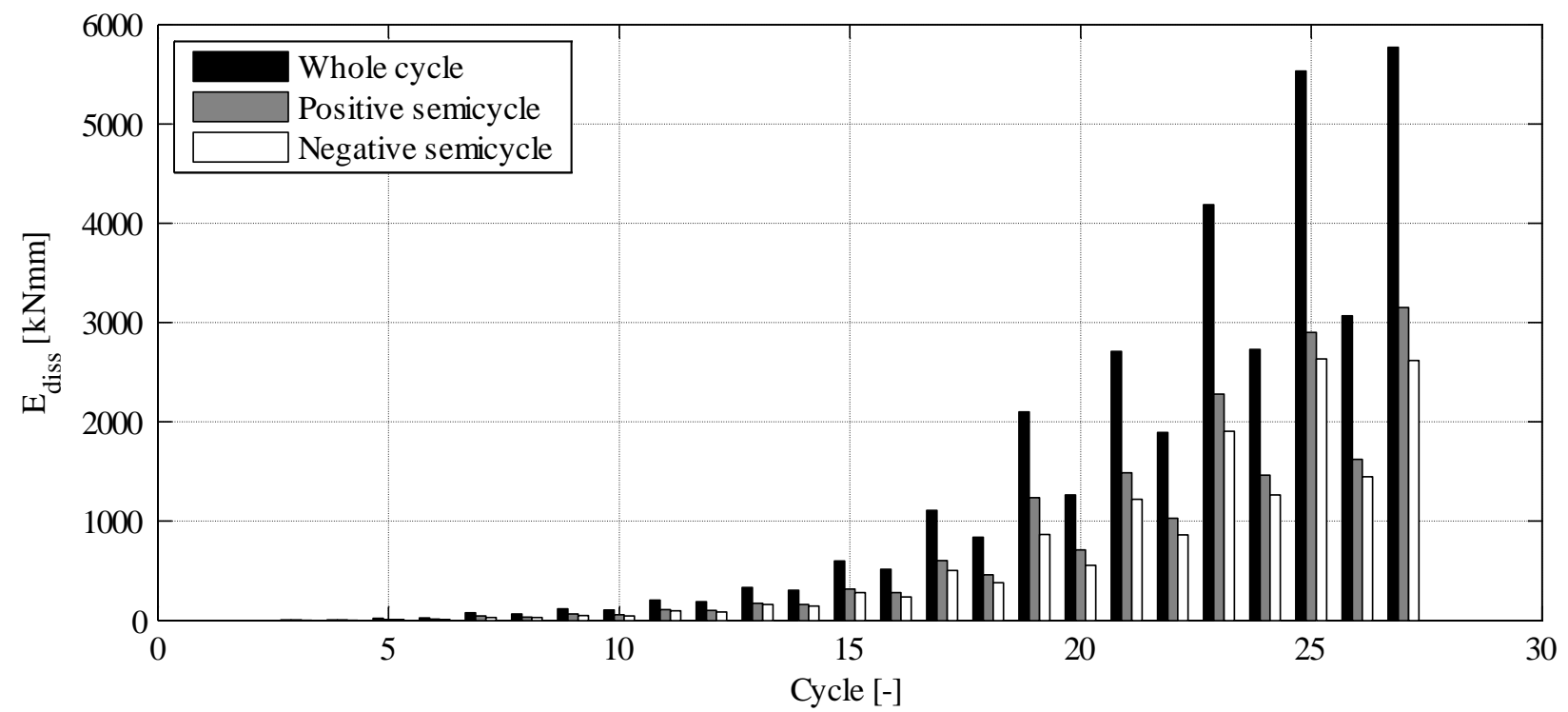

Figure 14. Energy dissipated in test no. 1 for each cycle of the protocol and each negative and positive semi-cycle.

The dissipated energy can be expressed in terms of equivalent viscous damping according to the following relationship [27]:

$$
\xi_{\text {eq }}=\frac{E_{D}}{4 \pi E_{S}}
$$

where $E_{D}$ is the dissipated energy, and $E_{S}$ is the maximum strain energy at a given cycle. The $\xi_{\text {eq }}$ values are evaluated for the $1^{\text {st }}$ cycle at each step and plotted versus the corresponding interstory drift ratio amplitudes in Figure 15. The tested partitions exhibit similar equivalent viscous damping trends. The equivalent viscous damping is notably large for the first cycles, i.e., 20-45\%, which confirms the friction-based behavior for low interstory drift demand (Figure 12a); the pinching- 
based behavior (Figure 12b) induces a reduction of the equivalent viscous damping for different tested specimens at large interstory drift ratio. However, the equivalent viscous damping is larger than $10 \%$, except in test no. 4 at the last step.

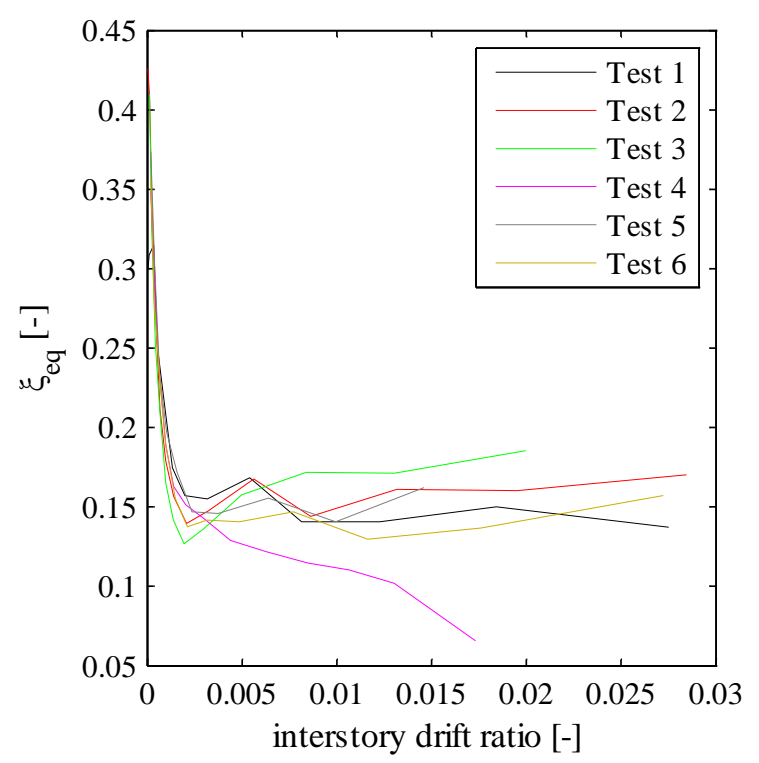

Figure 15. Equivalent viscous damping trend for different tests.

The strain gauge (Figure 6) recordings on steel studs and plasterboards (Figure 16) lead to the following observations:

- the load is mainly carried by the plasterboards for low to moderate drift demands; then, the screwed connections start transferring the load from the boards to the studs, and the steel strains increase until the steel stud buckling occurs;

- the steel strain trend shows the stud buckling during the test: after buckling occurs, the strain gauges record mainly the tensile strains (positive strains in Figure 16a) in the steel stud;

- the large strains in sg3 and sg4 confirm that the demand in the steel stud is concentrated across the horizontal joints. 


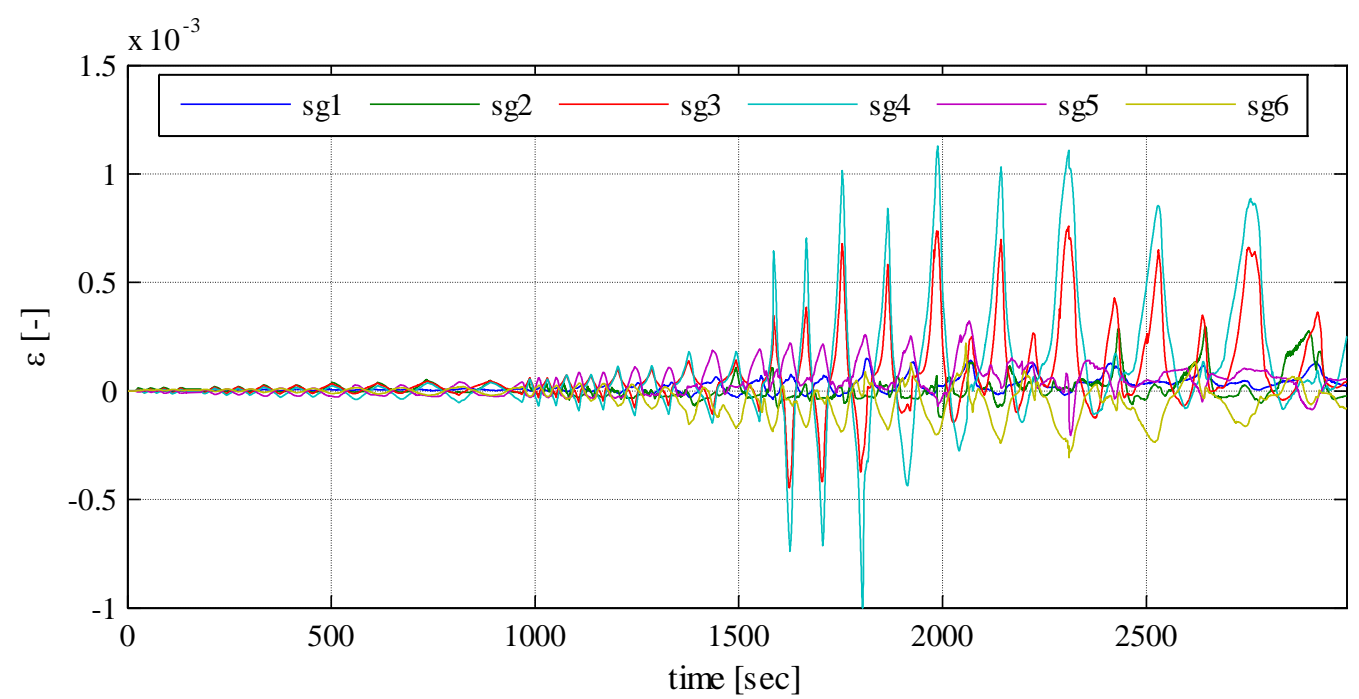

(a)

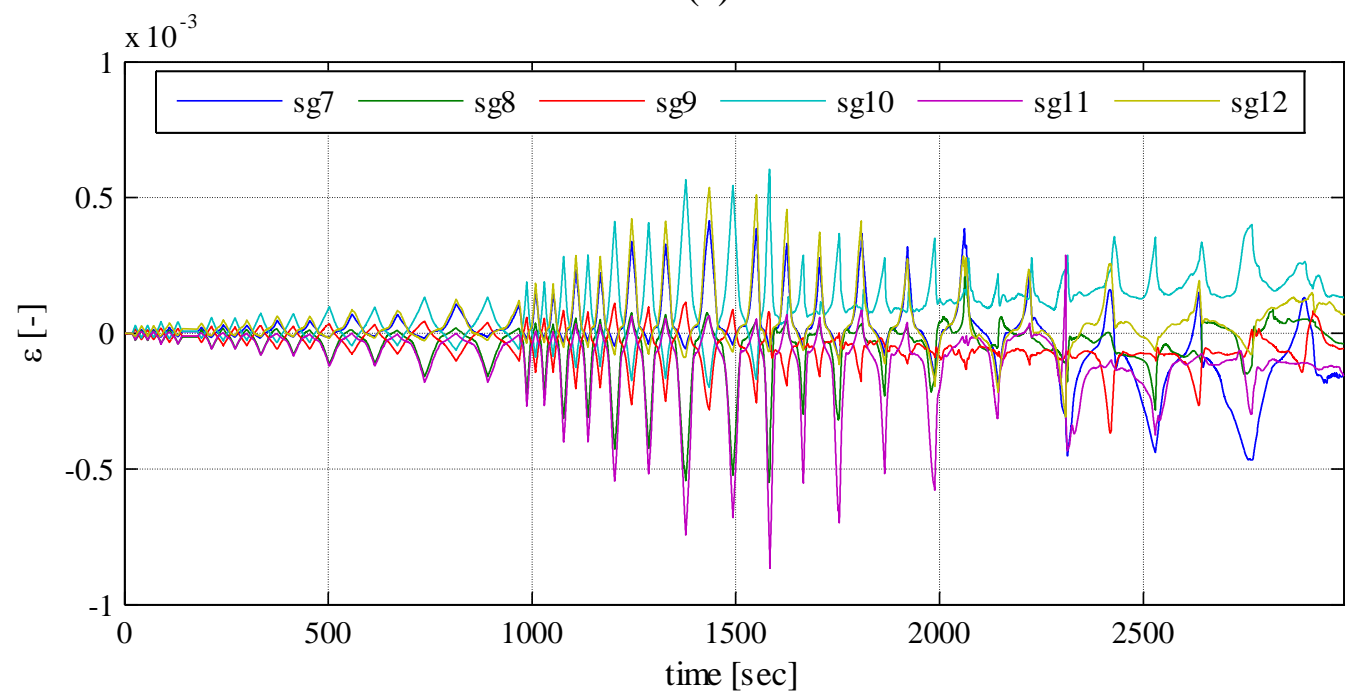

(b)

Figure 16. Strain gauge recordings in (a) steel studs and (b) plasterboards in test no. 2.

\subsection{DS-EDP correlation and fragility curve evaluation}

The correlation between a set of damage states (DS) and an engineering demand parameter (EDP) assumes a key role in defining the fragility curve. In this study, three damage states were considered for the seismic response definition of the plasterboard partitions: DS1, DS2 and DS3, and the interstory drift ratio (IDR) was considered the engineering demand parameter. The occurrence of DS1 implies limited and minor damage in the component, which can be easily repaired to restore the original conditions; the DS2 achievement implies that the component must be partially removed and replaced; DS3 implies that either life safety is not ensured or the partition must be totally replaced.

To correlate the observed damage to a defined damage state, a "damage scheme" was defined (Table 4). In particular, the damage level required to reach a given damage state is indicated for each component of the partition. Obviously, the damage state of studs, tracks and part of the screws can be observed only at the end of each test after dismantling the plasterboards. 


\begin{tabular}{|c|c|c|c|}
\hline Component & Damage State 1 (DS1) & Damage State 2 (DS2) & Damage State 3 (DS3) \\
\hline Plasterboards & $\begin{array}{l}\text { Drop of gypsum dust, small } \\
\text { slip between adjacent panels } \\
(<2 \mathrm{~mm}) \text {, minor detachment } \\
\text { with respect to lateral borders } \\
\qquad(<5 \mathrm{~mm})\end{array}$ & $\begin{array}{l}\text { Out-of-plane rotation between } \\
\text { adjacent panels, slight crack } \\
\text { ( } \leq 0.3 \mathrm{~mm} \text { wide) in the panel, } \\
\text { panel portion failure }\end{array}$ & $\begin{array}{l}\text { Expulsion of a partition portion, out- } \\
\text { of-plane rotation between adjacent } \\
\text { panels, large cracks on panels ( }>0.3 \\
\text { mm wide) }\end{array}$ \\
\hline Steel studs & - & $\begin{array}{l}\text { Local plastic deformations, } \\
\text { small bump on the flanges, } \\
\text { buckling deformations of the } \\
\text { web }\end{array}$ & $\begin{array}{l}\text { Buckling failure of a stud, large out- } \\
\text { of-plane displacement }(\mathrm{d} / \mathrm{h} \geq 1 / 200) \text {, } \\
\text { diffused local plastic deformation on } \\
\text { flanges or web, dislodgement from the } \\
\text { top or base track }\end{array}$ \\
\hline Steel tracks & - & Localized plastic deformations & $\begin{array}{c}\text { Permanent displacements, spread } \\
\text { plastic deformations, buckling failure } \\
\text { of the web or of a flange }\end{array}$ \\
\hline Screws & - & $\begin{array}{l}\text { Unscrewing of few screws } \\
(\leq 5 \%) \text {, bearing failure of the } \\
\text { screws connecting plasterboard } \\
\text { panels to metal studs and tracks } \\
(\leq 5 \%)\end{array}$ & $\begin{array}{l}\text { Unscrewing of several screws }(>5 \%) \text {, } \\
\text { bearing failure and expulsion of the } \\
\text { screws connecting plasterboard panels } \\
\text { to metal studs and tracks }(>5 \%)\end{array}$ \\
\hline $\begin{array}{l}\text { Paper and } \\
\text { compound }\end{array}$ & $\begin{array}{l}\text { Visible opening in the joints } \\
\text { paper on lateral borders or } \\
\text { horizontal and vertical joints }\end{array}$ & - & - \\
\hline
\end{tabular}

Table 4. Damage scheme for the correlation between the recorded damage in each component of the partition and the attained damage state.

The correlation between the damage state (DS) and the interstory drift ratio (IDR) is shown in Table 5 for each performed test.

\begin{tabular}{cccc}
\hline & $\underline{\text { DS1 }}$ & $\underline{\text { DS2 }}$ & $\underline{\text { DS3 }}$ \\
\hline$\underline{\text { Test no. } 1}$ & 3.39 & 8.74 & 27.81 \\
\hline Test no. 2 & 1.56 & 9.12 & 29.20 \\
\hline$\underline{\text { Test no. } 3}$ & 3.23 & 8.86 & 20.45 \\
\hline Test no. 4 & 3.23 & 11.55 & 16.14 \\
\hline Test no. 5 & 2.44 & 4.22 & 10.94 \\
\hline Test no. 6 & 3.42 & 8.30 & 25.46 \\
\hline
\end{tabular}

Table 5. Interstorey drift ratio (IDR) [\%o] where the considered damage states (DS) occur for different performed tests.

First, it should be noted that the IDRs that cause the DS3 achievement are larger than the limitation provided by current Italian and European building codes, i.e., 5-10\% drift, for both symmetric and staggered specimens.

Staggered partitions exhibit a worse behavior than symmetric partitions because of their geometry: they are less stiff than symmetric ones in the out-of-plane direction; thus, they tend to buckle at lower drift levels.

A fragility curve evaluation was performed according to the data in Table 5 . The procedure in Porter et al. [28] (Method A) was used, where the fragility parameters are computed as:

$$
\begin{gathered}
x_{m}=\exp \left(\frac{1}{M} \cdot \sum_{i=1}^{M} \ln r_{i}\right) \\
\beta_{\text {mod }}=\sqrt{\frac{1}{M-1} \sum_{i=1}^{M}\left(\ln \left(r_{i} / x_{m}\right)\right)^{2}+\beta_{u}^{2}}=\sqrt{\beta_{f i t}^{2}+\beta_{u}^{2}}
\end{gathered}
$$

where $M$ is the number of tested specimen, $r_{i}$ is the interstorey drift ratio (IDR) where a given damage state occurs in the $\mathrm{i}$-th specimen, and $\beta_{u}$ is 0.25 because all specimens are subjected to the same loading history [29]. The fragility curves for the three considered damage states are plotted in Figure 17. The fragility curves that fit the experimental data (dashed thick lines in Figure 17) are 
clearly highlighted; a solid line denotes the fragility curves that are characterized by an increased dispersion $\beta_{\text {mod }}$ (solid thick lines in Figure 17), which also considers the logarithmic standard deviation $\beta_{u}$. The fragility curves satisfy the Lilliefors goodness-of-fit test [30] with a 5\% confidence level.

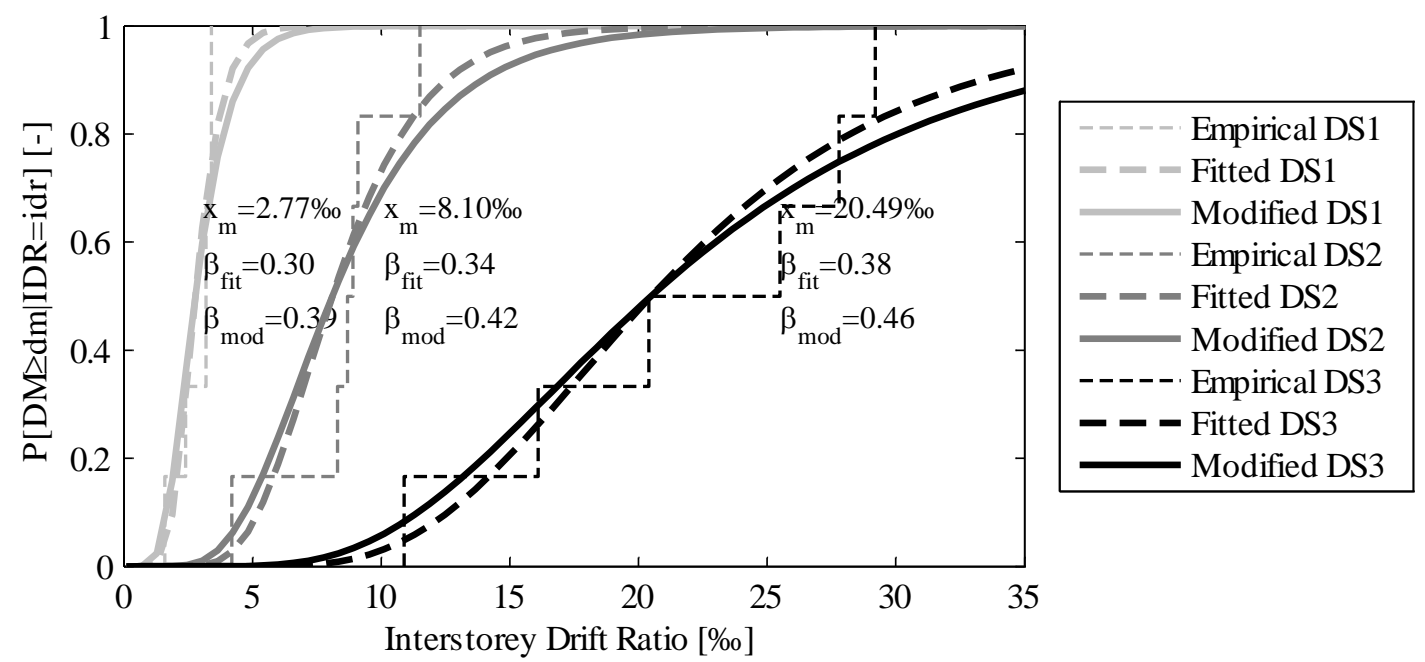

Figure 17. Fragility curves for the considered damage states for the tested specimens. The dashed thick lines are the fragility curves that fit the experimental data (dashed lines); the solid thick lines are the fragility curves that include a larger standard deviation because of the use of the same loading protocol for the different specimens

[29].

The median IDR values that cause DS2 and DS3 are slightly larger than the ones evaluated by Retamales et al. [16], i.e., 6.7\%o and 10.5\% for DS2 and DS3, respectively; however, the logarithmic standard deviations are in the same order of magnitude. The difference in the DS2 and DS3 median IDR values may be justified by the larger flexibility because of the larger number of horizontal plasterboards joints and the non-connection of the studs to the tracks in the tested $5 \mathrm{~m}$ high partitions. Moreover, the specimens tested by Retamales et al. [16] are representative of typical US partitions. Their different construction details, e.g., mechanical properties of boards and screws, may have caused a different seismic performance compared to the European specimens.

\section{CONCLUSIONS}

Quasi-static tests were performed on $5 \mathrm{~m}$ high plasterboard internal partitions that are typically commercialized in Europe for industrial buildings.

A steel test setup was designed to transfer the load from a hydraulic jack to the partition without absorbing lateral forces. Six different representative specimens of European typical partition typologies were tested. The specimens were subjected to the quasi-static testing protocol of FEMA 461. The testing protocol, which was defined upon US ground motions, was adapted to a set of European ground motions; a minor modification to the existing testing protocol was provided.

The specimens collapse in the out-of-plane direction because of the buckling of a steel stud, which involves the boards that are attached to the buckled stud. The buckling failure concentrates at the plasterboard horizontal joints.

The hysteretic loops show a frictional behavior for low interstory drift demand levels; a strongly pinched behavior is exhibited when the panel-to-stud screwed connections begin to be damaged. Moreover, the degrading behavior of the specimen is clearly observed in the energy dissipated in two consecutive cycles.

The correlation between a set of three damage states (DS1, DS2 and DS3) and an engineering demand parameter, i.e., the interstory drift ratio (IDR), was evaluated using a predefined damage scheme. Based on the experimental data, which were evaluated using the performed tests, the fragility curves for three different damage states were evaluated. Their evaluation yields median 
IDR values of $0.28 \%, 0.81 \%$ and $2.05 \%$ and logarithmic standard deviations of $0.39,0.42$ and 0.46 for DS1, DS2 and DS3, respectively.

\section{ACKNOWLEDGEMENTS}

This study was funded by both the Italian Department of Civil Protection in the frame of the national project DPC - ReLUIS 2014 RS8 and Siniat, which also provided the partition systems for the testing program.

The support provided by Eng. Giuseppe Campanella and Eng. Marco Russo during the test execution and result analysis is gratefully acknowledged. The authors thank Ms. Raffaelina Divano, the English language expert, for proofreading the paper.

\section{REFERENCES}

[1] Bertero RD, Bertero VV. Performance-based seismic engineering: the need for a reliable conceptual comprehensive approach. Earthquake Engineering \& Structural Dynamics 2002; 31 (3): 627-652. DOI:10.1002/Eqe.146.

[2] Taghavi S, Miranda E. Response assessment of nonstructural building elements, PEER report 2003/05. College of Engineering, University of California Berkeley, USA, 2003.

[3] Earthquake Engineering Research Institute (EERI). Nonstructural Issues of Seismic Design and Construction, Publication 84-04. Berkeley, CA, USA, 1984.

[4] Magliulo G, Ercolino M, Petrone C, Coppola O, Manfredi G. The Emilia Earthquake: the Seismic Performance of Precast Reinforced Concrete Buildings. Earthquake Spectra 2014; 30 (2): 891-912. DOI:10.1193/091012EQS285M.

[5] Villaverde R. Seismic design of secondary structures: State of the art. Journal of Structural Engineering-Asce 1997; $123 \quad$ (8): 1011-1019. DOI:10.1061/(Asce)07339445(1997)123:8(1011).

[6] Furukawa S, Sato E, Shi Y, Becker T, Nakashima M. Full-scale shaking table test of a baseisolated medical facility subjected to vertical motions. Earthquake Engineering \& Structural Dynamics 2013; 42 (13): 1931-1949. DOI:10.1002/eqe.2305.

[7] Kuo K-C, Suzuki Y, Katsuragi S, Yao GC. Shake table tests on clutter levels of typical medicine shelves and contents subjected to earthquakes. Earthquake Engineering \& Structural Dynamics 2011; 40 (12): 1367-1386. DOI:10.1002/eqe.1094.

[8] Magliulo G, Pentangelo V, Maddaloni G, Capozzi V, Petrone C, Lopez P, Talamonti R, Manfredi G. Shake table tests for seismic assessment of suspended continuous ceilings. Bulletin of Earthquake Engineering 2012; 10 (6): 1819-1832. DOI:10.1007/s10518-0129383-6.

[9] Badillo-Almaraz H, Whittaker AS, Reinhorn AM. Seismic fragility of suspended ceiling systems. Earthquake Spectra 2007; 23 (1): 21-40. DOI:10.1193/1.2357626.

[10] Lee TH, Kato M, Matsumiya T, Suita K, Nakashima M. Seismic performance evaluation of non-structural components: Drywall partitions. Earthquake Engineering \& Structural Dynamics 2007; 36 (3): 367-382. DOI:10.1002/Eqe.638.

[11] Restrepo JI, Lang AF. Study of Loading Protocols in Light-Gauge Stud Partition Walls. Earthquake Spectra 2011; 27 (4): 1169-1185. DOI:10.1193/1.3651608.

[12] Restrepo JI, Bersofsky AM. Performance characteristics of light gage steel stud partition walls. Thin-Walled Structures 2011; 49 (2): 317-324. DOI:10.1016/j.tws.2010.10.001.

[13] Tasligedik AS, Pampanin S, Palermo A. Damage states and cyclic behaviour of drywalls infilled within rc frames. Bulletin of the New Zealand Society for Earthquake Engineering 2012; 45 (2): 84-94.

[14] Magliulo G, Petrone C, Capozzi V, Maddaloni G, Lopez P, Manfredi G. Seismic performance evaluation of plasterboard partitions via shake table tests. Bulletin of Earthquake Engineering 2014; 12 (4): 1657-1677. DOI:10.1007/s10518-013-9567-8. 
[15] Magliulo G, Petrone C, Capozzi V, Maddaloni G, Lopez P, Talamonti R, Manfredi G. Shake Table Tests on Infill Plasterboard Partitions. The Open Construction and Building $\begin{array}{llllll}\text { Technology Journal 2012; } 6 & 6 & \text { (Suppl } & 1-M 10):\end{array}$ DOI:10.2174/1874836801206010155.

[16] Retamales R, Davies R, Mosqueda G, Filiatrault A. Experimental Seismic Fragility of ColdFormed Steel Framed Gypsum Partition Walls. Journal of Structural Engineering 2013; 139 (8): 1285-1293. DOI:10.1061/(ASCE)ST.1943-541X.0000657.

[17] FEMA 461. Interim Testing Protocols for Determining the Seismic Performance Characteristics of Structural and Nonstructural Components. Redwood City, California, USA, 2007.

[18] CEN. Eurocode 3: design of steel structures - Part 1-1: General rules and rules for buildings. EN 1993-1-1. Brussels, Belgium, 2005.

[19] CEN. Eurocode 3: design of steel structures - Part 1-8: design of joints. EN 1993-1-8. Brussels, Belgium, 2005.

[20] Krawinkler H, Parisi F, Ibarra L, Ayoub A, Medina R. Development of a Testing Protocol for Wood Frame Structures. CUREE Publication No. W-02, Consortium of Universities for Research in Earthquake Engineering: Richmond, CA, USA, 2001.

[21] Magliulo G, Maddaloni G, Cosenza E. Extension of N2 method to plan irregular buildings considering accidental eccentricity. Soil Dynamics and Earthquake Engineering 2012; 43 (1): 69-84. DOI:10.1016/j.soildyn.2012.07.032.

[22] Magliulo G, Ercolino M, Manfredi G. Influence of cladding panels on the first period of one-story precast buildings. Bulletin of Earthquake Engineering 2015; 13 (5): 1531-1555. DOI:10.1007/s10518-014-9657-2.

[23] ASTM. Standard Practices for Cycle Counting on Fatigue Analysis. ASTM-1049, American Society for Testing and Materials: West Conshohocken, PA, USA, 2003.

[24] British Standards Institution. EN 520:2004. Gypsum plasterboards - Definitions, requirements and test methods. London, UK, 2004.

[25] British Standards Institution. EN 14195:2005. Metal framing components for gypsum plasterboard systems - Definitions, requirements and test methods. London, UK, 2005.

[26] British Standards Institution. EN 14566:2008. Mechanical fasteners for gypsum plasterboard systems - Definitions, requirements and test methods. London, UK, 2008.

[27] Chopra AK, Dynamics of structures: Theory and Applications to Earthquake Engineering, Englewood Cliffs, New Jersey, USA, Prentice Hall, 1995.

[28] Porter K, Kennedy R, Bachman R. Creating Fragility Functions for Performance-Based Earthquake Engineering. Earthquake Spectra 2007; 23 (2): 471-489. DOI:10.1193/1.2720892.

[29] Porter K, Kennedy R, Bachman R. Developing Fragility Functions for Building Components for ATC-58. A Report to ATC-58. Applied Technology Council, Redwood City, CA, US, 2006.

[30] Lilliefors HW. On the Kolmogorov-Smirnov Test for Normality with Mean and Variance Unknown. Journal of the American Statistical Association 1967; 62 (318): 399-402. DOI:10.2307/2283970. 